\title{
Changing Risk Perception and the Time-Varying Price of Risk*
}

\author{
Roland Füss ${ }^{1}$, Thomas Gehrig ${ }^{2}$ and Philipp B. Rindler ${ }^{3}$ \\ ${ }^{1}$ Swiss Institute of Banking and Finance, University of St.Gallen, and ZEW, Mannheim; \\ ${ }^{2}$ Department of Finance, University of Vienna, and CEPR, London; ${ }^{3}$ Department of \\ Management, Technology, and Economics, ETH Zürich
}

\begin{abstract}
This paper investigates the impact of changes in risk perception on bond markets triggered by the 2007-08 financial crisis. Using a methodology novel to empirical finance, we quantify the increase in credit spreads caused by changes in risk pricing and changes in risk factors. The lasting increase in credit spreads is almost exclusively due to time-varying prices of risk. We interpret this as a change in risk perception which provides a possible solution to the credit spread puzzle. Default premia spiked during the crisis and did not return to their pre-crisis levels. Liquidity premia increased during and after the crisis.
\end{abstract}

JEL Classification: C21, G12

\section{Introduction}

During the 2007-08 financial crisis credit spreads for corporate bonds surged dramatically and have not returned to previous levels. Figure 1 illustrates the evolution of US corporate credit spreads for the period October 2004 to June 2011. There are, at least, two potential explanations for this observation. Either the crisis has not completely vanished and the underlying risk factors remained elevated, or the crisis did cause a change in the underlying pricing of risk, enhancing the required yield that investors charge for holding

\footnotetext{
${ }^{*}$ A previous version of this paper was circulated under the title: Did the 2007-08 Financial Crisis Change Risk Perceptions? This is a revised version of CEPR-DP. 8714. We are grateful to Bernard Dumas (editor) and an anonymous referee for valuable suggestions which have significantly improved the paper. We are also indebted to Dirk Antonczyk, Chris Brooks, Martin Brown, Rasa Karapandza, Michael Landesmann, Giovanna Nicodano, Marcel Prokopczuk, Daniel Ruf, Paul Söderlind, Monika Trapp, Clemens Völkert, and Jan Wrampelmeyer as well as the participants of the 2011 European Meeting of the Econometric Society, the 2011 International Conference on Credit Analysis and Risk Management, the 2012 Conference on Liquidity and Credit Risk, the 2012 Annual Meeting of the German Finance Association and the research seminar of the University of Linz for useful comments and helpful suggestions.
}

(C) The Author 2015. Published by Oxford University Press on behalf of the European Finance Association. All rights reserved. For Permissions, please email: journals.permissions@ oxfordjournals.org 


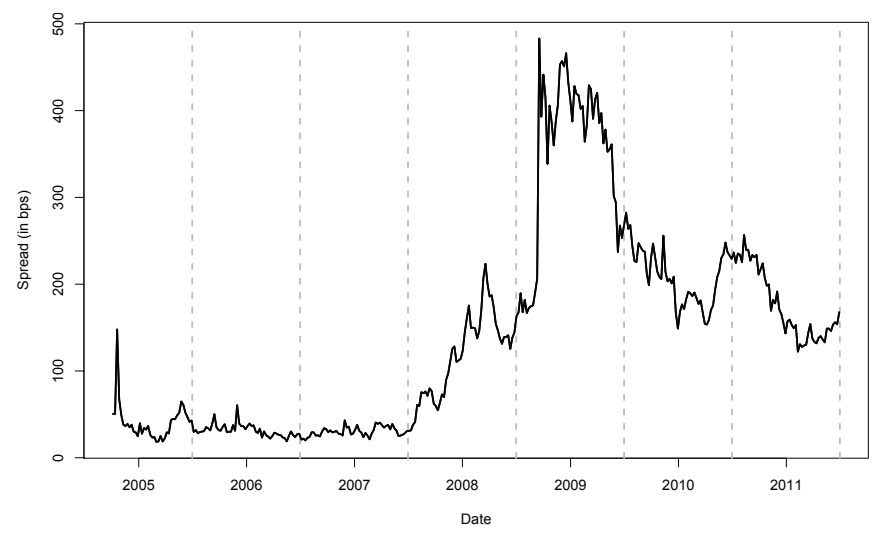

Fig. 1. Development of US Corporate Credit Spreads (October 2004 - June 2011). The chart shows the weekly market-wide corporate bond yield spread between October 2004 and June 2011 computed as the median spread of US corporate bonds. The spread is measured relative to the swap rate curve and reported in basis points.

the bonds. Essentially, the latter implies that investors risk attitudes may have changed in the course of the crisis.

The change in the risk premium may reflect changing risk attitudes, or simply sentiment in the words of Shefrin (2001). Shefrin, as well as Barone-Adesi, Mancini, and Shefrin (2014) provide a framework to incorporate such a change in risk attitudes into standard asset pricing models by decomposing the (logarithmic) stochastic discount factor into a standard fundamental process and another additive process reflecting changing risk attitudes. ${ }^{1}$ This additive process can nicely generalize the standard asset pricing framework to incorporate non-monotonic stochastic discount factor functions reflecting behavioral features such as changing sentiment, and consequently, time-varying prices of risk. $^{2}$

The financial crisis of 2007-08 was sufficiently severe that it might have affected both, risk factors as well as risk attitudes. Therefore, in this paper we present a methodology novel to asset pricing in order to separate these two effects. Using decomposition methods along the lines of Oaxaca-Blinder (Oaxaca (1973), Blinder (1973)), we investigate and quantify empirically how the financial crisis and the corresponding change in risk taking of institutional investors has altered the pricing of risk in the corporate bond market. We use the current financial crisis as a trigger event for a fundamental change in risk perception. In our identification, we then construct estimates of the distribution of credit spreads that would have prevailed after the financial crisis if the crisis had not altered the way risk factors are priced. After controlling for changes that our model cannot account for, we obtain an explicit estimate of how much of the total increase in the level of bond spreads has been caused by a general shift in risk perception by investors.

We use quantile regressions to model the relationship between risk factors and credit spreads, in order to exploit information on the full return distribution. We favor quantile

\footnotetext{
1 The notion that risk attitudes have affected price behavior in this crisis has also been mentioned in Shefrin (2009).

2 This approach contributes to resolving the pricing kernel puzzle (Hens and Reichlin, 2013).
} 
regression over the standard mean regression since it allows us to control for non-linearity in the pricing relationship of risk factors. For instance, one would expect that liquidity has different implications for high-yield bonds than for low-yield bonds. We examine the impact of factors related to default risk and liquidity risk as well as bond characteristics simultaneously in order to obtain a complete description of the conditional distribution of bond spreads. Moreover, to explain the total level of credit spreads, we derive economic hypotheses that explain the time-varying and non-linear nature of these risk premia, and thus, the impact of changing risk perception on corporate bond pricing.

While time-varying beta regressions or state-space models try to answer the question how the explanatory power can be improved when we assume that coefficients are timevarying, the impact of changes in perception could not be addressed in such a framework. Since risk factors and the pricing of factors change simultaneously, these models are unable to disentangle their separate contribution to variations in credit spreads. Hence, timevarying coefficients models are based on an explicit assumption about the relationship in the dynamics of factors and coefficients, which usually are taken as independent. The use of counterfactual distributions, on the other hand, provides direct estimates of those coefficient effects.

This paper also contributes to the empirical literature on time-varying risk premia on bond returns which is summarized in Giesecke, Longstaff, Schaefer, and Strebulaev (2011). These authors note that corporate bond spreads display considerable variations over time that do not appear to be closely related to economic fundamentals driving default risk. They also show the converse result, i.e., variables that help explaining credit spreads have little explanatory power to forecast corporate defaults. They interpret this as an indication that credit spreads are driven primarily by changes in credit and liquidity risk premia, and only marginally by changes in objective measures of default or liquidity risk. In this paper, we investigate this proposition explicitly, while adding the role of changing market perceptions, analogously to Lettau and Ludvigson (2001), who introduced time-varying risk premia for the case of equity markets.

In our data we find that almost the entire change in credit spreads is the result of increases in the premia of risk factors and not changes in the factor themselves. Comparing pre-crisis to crisis and post-crisis levels, we find that during the crisis given risk factors were priced much higher and that this increase did not revert after the crisis had abated. Comparing pre-crisis to crisis levels, we find that 25 to $50 \%$ of the increase in credit spreads is caused by an actual change of risk factors (depending on the quantile of the distribution). The remainder of the increase stems from the fact that the average risk premia have increased. Comparing the crisis period to the post-crisis period, we find that risk factors returned to their initial levels while the risk premia remained high. Thus, the decrease of credit spreads after the crisis was the result of the changing economic environment. The increase of credit spreads from the pre-crisis to post-crisis period is the result of increased risk premia in the bond market. Hence, most of the variation in bond spreads over the entire period of analysis is not attributable to a change in fundamentals, but almost entirely explained by a change in risk perception of the market. Otherwise, in terms of risk factors the market has returned to pre-crisis levels. This implies that risk perceptions must have changed. In fact, our analysis suggests that the overall risk bearing capacity of the bond market has been reduced significantly. Moreover, our estimates reflect the findings from the literature that a scary experience can induce a substantial increase in investors' risk aversion, and thus leads to changes in the pricing of factors from before to after the financial crisis. Our results also accord well with the questionnaire based evidence of Guiso, 
Sapienza, and Zingales (2013) for Italian investors and with the experimental evidence of Cohn, Engelmann, Fehr, and Maréchal (2014) about the countercyclical willingness to take risk of financial professionals after they have passed through a financial crisis period. Our paper complements this literature by demonstrating empirically the extent of the effects of changes in risk aversion. In particular, we demonstrate that the increase in bond spreads over the crisis is almost exclusively the result of changes in risk pricing and not caused by changes in market conditions.

We further decompose the total effect that changes in risk pricing had into the separate effects due to default and liquidity risk. We find a substantial increase in the pricing of default risk during the crisis which only slightly decreased again after the crisis. Default risk premia increases are larger for high-yield bonds than low-yield bonds. For liquidity factors, we find that premia increased both in the crisis and again after the crisis. For both time periods, we find that the increase in premia is roughly the same for all bonds. The results confirm the dominant role of liquidity in financial crises and particularly, its effect on the pricing of risky assets (see Allen and Carletti (2008) and Bacchetta, Tille, and van Wincoop (2012)). The finding of a level shift in the pricing of liquidity after the crisis compared to pre-crisis levels is in line with Bao, Pan, and Wang (2011), Dick-Nielsen, Feldhütter, and Lando (2012), and Friewald, Jankowitsch, and Subrahmanyam (2012) who also document an increase in liquidity effects during the crisis. These studies, however, do not consider a change in the underlying parameters as a consequence of the crisis.

The remainder of the paper is organized as follows. Section 2 reviews structural models of credit risk and the implications for the theoretical determinants of credit spreads. Based on this, it motivates the proxies we use in the empirical section and provides a definition of risk perception within an asset pricing framework. Section 3 introduces the data used and presents summary statistics. Section 4 presents the method of counterfactual analysis based on quantile regression. It also discusses how we use these ideas to provide a sequential decomposition of credit spreads as well as its underlying assumptions for the time-series dimension. The results on changes in risk pricing from our counterfactual experiment and the identification of the importance of risk factors by sequential decomposition are presented in Section 5. Section 6 concludes.

\section{Determinants of Credit Spreads}

Since we are interested in analyzing how changes in risk perception alter the pricing of risk we focus on relative risk premia. For corporate bonds, these risk premia are expressed in the respective yield spreads. In this section, we discuss the standard risk factors that can jointly explain the levels of credit spreads. We then provide a definition of risk perception within an asset pricing framework and derive our main hypotheses regarding the expected changes in risk premia in different states of the economy. Since the novel feature of our analysis is the estimation of the effects of changes in the pricing structure of the bond market, we then discuss possible explanations why investors would alter their perception of the fair yield premium of risk factors as a result of a deep financial crisis. ${ }^{3}$

\footnotetext{
3 Note that we do not derive a specific structural model to explain the underlying risk factors of credit spreads. Instead, we refer to existing models from literature to discuss the determinants of credit spreads and illustrate on the basis of the stochastic discount factor process their pricing behavior. A more formal model that is quite similar in spirit to our
} 


\subsection{Fundamental Bond Pricing Factors}

Credit. Structural models of credit risk are based on the idea that a company's default is triggered when the value of the firm's assets hits some lower boundary. Thus, these models predict that the difference in yields of corporate bonds above the yield of risk-free bonds arises because of the possibility of the firm defaulting on its debt and the uncertain reduction in payments due to such an event. Therefore, bonds of companies with a higher probability of default should exhibit higher credit spreads. In addition, higher volatility of the value of a firm as well as lower firm value should be associated with higher credit spreads. Empirically, defaults occur too infrequently to be consistent with the prediction that credit spreads arise only due to credit risk (see, e.g., Elton, Gruber, Agrawal, and Mann (2001)). Moreover, Huang and Huang (2012) show that structural models based only on default risk generate credit spreads that are much too low compared to observed spread. This phenomenon is commonly called the credit spread puzzle. These observations have led to a large number of investigations into additional determinants of credit spreads.

Liquidity. There are two main arguments why there should be a premium for liquidity. The first dates back to the idea of Amihud and Mendelson (1986) that investors require compensation for holding illiquid assets. Hence, the level of liquidity of an asset should influence its market price. Following this argument, Chen, Lesmond, and Wei (2007) provide direct evidence that both investment and speculative bonds carry an illiquidity premium. In complementary work, Bao, Pan, and Wang (2011) provide further evidence of the importance of liquidity as a determinant of the levels of credit spreads observed on markets. The second theoretical rationale why liquidity is expected to explain corporate bond spreads is based on the liquidity-adjusted capital asset pricing model of Acharya and Pedersen (2005). They show that expected returns depend on the covariance of an asset with market liquidity. Thus, liquidity risk should be a priced characteristic on asset markets. Lin, Wang, and Wu (2011) study this relation and find a strong association between corporate bond returns and systematic liquidity risk. Longstaff, Mithal, and Neis (2005) conclude that, even though the majority of credit spreads is due to default risk, the non-default component is strongly influenced by (il-)liquidity. Hence, there should be a negative (positive) relationship between measures of liquidity (illiquidity) and bond spreads.

\subsection{Changing Risk Perception and the Pricing of Risk}

Related Literature. There are various reasons why large shocks may have lasting effects on risk perceptions. First, there may be learning about the parameters that drive the economy. Papers such as Timmermann (2001), Kim (2006), or Bansal and Shaliastovich (2011) imply that once investors realize that a structural break has occurred they will start to learn about the new parameters with adaptive learning rules. This learning introduces long-run risk resulting in permanent shifts after large shocks (see, e.g. Collin-Dufesne, Johannes, and Lochstaer (2013)). This theory is confirmed by Malmendier and Nagel (2011) who show that the willingness to take risk of private household investors are shaped by personal experience of macroeconomic shocks. Similarly, Cohn, Engelmann, Fehr, and Maréchal (2014) find experimental evidence that financial professionals confronted with

empirical analysis can be found in Boyarchenko (2012) and Chen, Cui, He, and Milbradt (2014). 
a financial bust were more risk-averse than those who only experienced a boom phase. These two examples for the experience hypothesis demonstrate that a financial shock such as the recent financial crisis leads to countercyclical risk aversion and amplifies market dynamics. Second, uncertainty about the state of the economy may cause ambiguity averse investors to assign higher probabilities on the possibility of a low utility state recurring after just such an event has occurred. Gagliardini, Porchia, and Trojani (2009) show that an ambiguity about a state variable can induce a large yield premium. Boyarchenko (2012) uses a model with both ambiguity about information quality and model quality to explain the rapid increase in CDS spreads during the financial crisis. Third, as modeled by Drechsler (2013), concerns by investors about model misspecification can strongly impact risk premia. Fourth, as argued by Guiso, Sapienza, and Zingales (2013), the crisis might have altered the determinants for variations in risk aversion such as changes in wealth, changes in habits, and changes in background risk. Finally, Bacchetta, Tille, and van Wincoop (2012) show that self-fulfilling shifts in risk are made possible when asset prices depend negatively on perceived risk of future asset prices. Hence, there are many explanations why risk perceptions should change. However, there is a lack of empirical evidence that documents the magnitude of the effect. In this paper, we seek to quantify how much of the variation in credit spreads is due to changing risk perception and how much is caused by changing risk. It is well known that structural models cannot match observed credit spreads giving rise to the credit spread puzzle. Our results complement recent theoretical results by Chen (2010) and Chen, Cui, He, and Milbradt (2014) on the importance of macroeconomic conditions for explaining the levels and changes of credit spreads. Our empirical results complement their theoretical predictions by showing that changes in the pricing of risk are of first-order importance. We thus provide an important mosaic to solve the credit spread puzzle.

Hypotheses. During an economic crisis, marginal utility from investment income increases and therefore risk premia should rise as well. For the bond market, the model by Chen (2010) makes this link precise by using recursive preferences. He shows that countercyclical variation in risk prices, default probabilities, and default losses for bond and equity holders lead to increased credit spreads in bad economic states. Default probabilities and default losses increase because lower growth rates of the cash flow of firms and increased economic uncertainty reduces the continuation value of a firm and reduces the liquidation value of assets. The model also implies that premia for default risk react to aggregate default risk. Hence, when defaults cluster, for example during a recession, credit risk premia of other firms should jump up in response. To the extent that high asset growth rates are indicative of high cash flow growth rates and low asset volatility of smaller economic uncertainty about the firm, the model also implies that firms with a good and stable performance should have lower credit spreads. This effect is particularly important during recessions because their continuation value will be less affected by the business cycle. As investors will be willing to pay a premium for these firms, we expect to find that firms with high asset volatility to have increased credit spreads during the crisis. The model by Chen (2010) abstracts from liquidity effects. The results of Dick-Nielsen, Feldhütter, and Lando (2012) establish, however, that liquidity dried-up during the crisis and that liquidity risk premia increased sharply.

Following these arguments, we define risk perception as changes to the mapping from payoffs to prices. Abstractly, any asset pricing model can be represented in a stochastic 
discount factor model:

$$
p_{t}=\mathbb{E}_{t}\left[\frac{\Lambda_{T}}{\Lambda_{t}} X\right]=\mathbb{E}_{t}^{\mathbb{Q}}\left[e^{-\int_{t}^{T} r_{u} d u} X\right]
$$

, where $p_{t}$ is the price of the asset, $X$ is its time- $T$ payoff and $\Lambda$ is an exogenous SDF. In the case of corporate bonds, the payoff $X$ is mainly affected by two sets of factors: The possibility of default and illiquidity. Following the reduced-form model by Duffie and Singleton (1999), the payoff $X$ is determined by the realization of a default intensity process $\lambda_{t}$ and a process for the cost of illiquidity $\gamma_{t}$. Hence, the price of a bond is given by

$$
p_{t}=\mathbb{E}_{t}\left[\frac{\Lambda_{T}}{\Lambda_{t}} e^{-\int_{t}^{T}\left(\lambda_{u}+\gamma_{u}\right) d u}\right]
$$

and the dynamics of the SDF follow

$$
\frac{d \Lambda_{t}}{\Lambda_{t}}=-r_{t} d t-\Theta d B_{t}
$$

where $B_{t}$ is a $d$-dimensional Brownian motion and the market price of risk $\Theta$ is given by

$$
\boldsymbol{\Sigma} \Theta=\boldsymbol{\mu}-r_{t} \mathbf{1}
$$

with $\boldsymbol{\Sigma}$ denoting the covariance matrix of the priced assets and $\boldsymbol{\mu}$ their expected returns. Holding fixed the SDF process (or fixing the pricing measure $\mathbb{Q}$ ), higher risk of default and higher levels of illiquidity will decrease the price $p_{t}$ of the bond in question. These are therefore the priced risk factors. By changes in risk perception, we refer to changes in the SDF used for pricing and in particular changes to the market price of risk. Hence, risk perception refers to the mapping from given levels of risk factors to the price $p_{t}$. Equivalently, we can interpret changes to risk perception as changes to the pricing measure $\mathbb{Q}$. As the risk-neutral probabilities are actually state-prices, these can change if either the state probabilities change or the marginal utility in different states change. As the discussed literature in the paper shows, large crises tend to both amplify the perceived probability of very negative outcomes as well as decrease the marginal utility of these outcomes. Both effects contribute to different risk perception.

In the model of the bond price in (1), the credit spread above the risk-free rate is given by

$$
s(t, T)=-\frac{\ln \left(\mathbb{E}_{t}\left[\frac{\Lambda_{T}}{\Lambda_{t}} e^{-\int_{t}^{T}\left(\lambda_{u}+\gamma_{u}\right) d u}\right]\right)}{T-t}+\frac{\ln \left(\mathbb{E}_{t}\left[\frac{\Lambda_{T}}{\Lambda_{t}}\right]\right)}{T-t} .
$$

Hence,

$$
\begin{aligned}
& s(t, T)=\frac{\ln \left(\mathbb{E}_{t}\left[\frac{\frac{\Lambda_{T}}{\Lambda_{t}}}{\mathbb{E}_{t}\left[\frac{\Lambda_{T}}{\Lambda_{t}}\right]} e^{-\int_{t}^{T}(\lambda u+\gamma u) d u}\right]\right)}{\ln \left(\mathbb{E}_{t}^{\mathbb{Q}}\left[\frac{e^{-\int_{t}^{T} r_{u} d u}}{\left[\mathbb{E}_{t}^{\mathbb{Q}}\left[e^{-\int_{t}^{T} r_{u} d u}\right]\right.} e^{-\int_{t}^{T}\left(\lambda_{u}+\gamma u\right) d u}\right]\right)} . \\
&=-\frac{T-t}{T} .
\end{aligned}
$$


If $e^{-\int_{t}^{T} r_{u} d u}$ and $e^{-\int_{t}^{T}\left(\lambda_{u}+\gamma_{u}\right) d u}$ are independent under $\mathbb{Q}$, then

$$
s(t, T)=-\frac{\ln \left(\mathbb{E}_{t}^{\mathbb{Q}}\left[e^{-\int_{t}^{T}\left(\lambda_{u}+\gamma_{u}\right) d u}\right]\right)}{T-t} .
$$

It is naturally to assume that the default and liquidity processes depend on some state variables, i.e. $\lambda_{t}=\Lambda\left(X_{t}\right)$ and $\gamma_{t}=\Gamma\left(X_{t}\right)$. The relevant state variables should be variables that relate to the probability of default and the level of liquidity discussed earlier in this section. The representation in (2) illustrates the roles that risk factors and risk perception play. Risk factors are relevant factors that allow investors to estimate the probability of default and likely levels of liquidity when trading a bond. Hence, these are the state variables that determine $\lambda_{t}$ and $\gamma_{t}$. Risk perception, however, relates to the mapping from these factors to prices, i.e. the realizations of the $\operatorname{SDF} \Lambda$. As the market prices of risk $\Theta$ change, so does the demanded credit spread for a given level of default or liquidity risk. ${ }^{4}$ The market price of risk could change, for instance, because of changes in the heterogeneity of beliefs among different agents, such as in Basak (2000), Dumas, Kurshev, and Uppal (2009), and Borovicka (2015), or because of heterogeneity in preferences, such as in Dumas (1989) and Bhamra and Uppal (2009), or a combination of both, as in Bhamra and Uppal (2014). Similarly, situations when agents are faced with changing portfolio constraints might also affect the price of risk (Prieto, 2013).

Based on the results in Chen (2010) and Dick-Nielsen, Feldhütter, and Lando (2012), we expect that pricing of default and liquidity risk factors substantially increase during the crisis compared to the pre-crisis period. After the crisis period, spreads did not return to their pre-crisis level. We hypothesize that this is mostly due to a change in the pricing of risk factors and not because the riskiness of bonds themselves have changed substantially. This expectation is motivated by the results in Boyarchenko (2012). Her model explicitly introduces ambiguity aversion into a Black and Cox (1976) type model of structural credit risk. This addition has two effects: Firstly, short-term credit spreads increase (relative to the ambiguity-neutral model) as ambiguity-averse investors place a higher probability of transition to low-utility states. This is similar to the effect that uncertainty about accounting information has on spread levels, as discussed in Duffie and Lando (2001). Secondly, the introduction of ambiguity aversion makes credit spreads react more strongly to new information as investors update their beliefs about default probabilities. Collin-Dufesne, Johannes, and Lochstaer (2013) show that shocks to rational beliefs, and thus, belief updating in terms of rational parameter learning lead to long-term consumption risk. ${ }^{5}$ They further emphasize that the same argument applies when there is model uncertainty and agents learn about previously unknown or underestimated parameters (see also Hansen (2007)). The authors can show that the impact of learning about variance of shocks and

${ }_{4}$ Equivalently, we can view Equation (2) from a risk-neutral pricing perspective. Since pricing is done under the risk-neutral measure, the probabilities of outcomes are actually state prices. Hence, risk perception in this sense relates to the price an investor is willing to pay to insure one unit of numéraire in a particular state of nature. Risk perception therefore changes when the marginal utility of consumption in a given state changes.

5 Note that uncertainty about the future first and second moments of consumption growth, particularly intertemporal consumption risk, affects the state-price density only if agents worry about intertemporal distribution of risk (see Bhamra, Kuehn, and Strebulaev (2010) and Chen (2010)). 
rare events on asset prices is, even though the belief shock is small, economically large and endogenously long-lasting. Chen, Collin-Dufesne, and Goldstein (2009) show that the credit spread puzzle can be resolved if one accounts for the fact that default rates and Sharpe ratios strongly covary. Based on this insight, the papers by Bhamra, Kuehn, and Strebulaev (2010) and Chen (2010) introduce a structural-equilibrium model, where, due to the assumption of risk-neutral probability of the economy switching from a good to a bad state, agents price assets as if the macroeconomic shock would last longer than is actually the case, and thus raises risk premiums when entering the bad state. Hence, in our framework risk aversion can be put on the level with parameter learning, which increases the price of risk even if the probability of a bad state in the economy is small. Moreover, the results of these papers support our hypothesis that the higher pricing of assets last longer than the bad state actually did, because agents prefer uncertainty to be resolved earlier.

Therefore, we assume that investors utilize the crisis as an event that generates information about the possibility of bad outcomes and, in that sense, allows them to update their assessment of risk. Observationally, this is equivalent to an exogenous increase in risk perception (Alary, Gollier, and Treich, 2010), even though it is rational inference from a crisis event. ${ }^{6}$ Experimental evidence for this type of behavior during a deep crisis is presented in Guerreri, Stone, and Sundali (2012).

Because the recent financial crisis was a liquidity crisis, i.e. bond investors suffered from a lack of liquidity and faced the risk of liquidity shocks, their costs for holding bonds increased sharply. More precisely, when secondary market liquidity deteriorated during the financial crisis, i.e. when the marginal utility of consumption is high, the liquidity risk premium in corporate bonds rises. This is all the more important as liquidity is a distinguishing feature of OTC markets, which are characterized by search frictions (see, e.g., Fecht, Füss, and Rindler (2014)). Consequently, we assume that both risk factors keep their absolute impact on bond spreads; however, we expect a relative shift towards a higher pricing of liquidity risk. As stated by Chen, Cui, He, and Milbradt (2014) "defaultdriven liquidity", i.e. the increase of liquidity risk which can be attributed indirectly to higher default risk rather than directly to the dry-up of liquidity, can cause such a relative shift in risk pricing. Another explanation for the relative importance of risk factors is that, even though the default probability might be small, default risk becomes more concentrated during the crisis period. Similarly, firm cash flows become more correlated, and thus, default risk is caused to be more systematic during phases of economic uncertainty. However, these systematic effects on default risk might diminish in the post-crisis period when economic uncertainty recedes and growth rates increase. Summing up, because of the above-mentioned experience hypothesis, we assume that after the financial crisis period investors are more concerned about liquidity and tend to price this risk factor higher relative to default risk.

There might be also other explanations of changes in the pricing of risk for which we cannot explicitly control in our empirical analysis. For instance, Basak and Cuoco (1998) show that in segmented markets where a proportion of agents are prevented from investing in stock markets due to information costs or other frictions, the consumption volatility of unrestricted agents increases. Consequently, in stock markets with limited participation the risk premium increases proportionally to the unrestricted agents risk aversion.

\footnotetext{
$\overline{6}$ The consequences are similar to a lack of liquidity resulting in increased volatility (Ghirardato and Marinacci, 2001).
} 


\section{Data and Descriptive Statistics}

The data sources for this study are CRSP, Compustat, the Mergent FISD (Fixed Income Securities Database), and FINRA's TRACE (Transaction Reporting and Compliance Engine) database. We consider the time frame from October 2004 until June 2011. The starting point of the sample is restricted by the fact that only in October 2004 did TRACE begin to report on all US bonds irrespective of their credit rating. We match companies across the databases based on their CUSIP number. We only include non-financial corporations as indicated by their GIC code. We are able to match 1,788 companies with a total of 8,411 bonds. We remove callable, putable, asset-backed, and convertible bonds as well as bonds that have sinking fund or any enhancing features. We restrict the sample to fixed-rate coupon bearing senior or super senior bonds. This leaves us with 5,186 bonds from 827 different corporations. All accounting data comes from Compustat. Most companies in the US report their yearly accounting statements by March. To ensure that markets fully incorporate the information contained therein, we measure all yearly values as of July $1^{\text {st }}$. For each company in the sample, we obtain daily equity returns as well as market values from CRSP.

Prior to using the TRACE data, we apply the following filters. We exclude any canceled, corrected, or duplicate interdealer trades as well as any trade where special conditions applied or comissions influenced the price. Moreover, we apply the median and reversal filters of Edwards, Harris, and Piwowar (2007). The former eliminates transactions for which reported prices deviate more than $30 \%$ from the median price of that day. The latter filter removes transactions with absolute price changes deviating from lead, lag, or average lead/lag changes by more than $10 \%$. To focus on institutional investors, we exclude all trades with retail size (trade value lower than $\$ 100,000$ ). Evidence by Goldstein, Hotchkiss, and Sirri (2007) suggests that trades below this threshold are mainly executed by retail investors, whereas trades above it are predominantly institutional trades (see also Feldhütter (2012)). We focus on institutional investors because retail investors have to bear higher transaction costs (see, e.g., Warga (2004) and Green, Hollifield, and Schürhoff (2007)) and thus perceive the corporate bond market to be relatively less liquid. According to Friewald, Jankowitsch, and Subrahmanyam (2012), however, we expect that institutional investors are more likely to be hit by liquidity shocks and react more strongly to changes in liquidity during the financial crisis. After these filters, we measure the yearly yield on each bond as the average yield of all trades on the last day the bond traded prior to July in each year. We only use bonds which have traded in the quarter before July. ${ }^{7}$ Finally, we remove all observations with yield spreads in the top and bottom $1 \%$ of the total sample. These are all bonds with either highly negative spreads or spreads above 5,000 bps.

As the risk-free rate, we use the constant maturity swap rate curve indices published by the US Treasury Department. We match the swap rates on the last trading day of each bond using linear interpolation between the two closest indices. We measure a bond's credit spread as the difference between its yield and the corresponding swap rate in basis points (bps). We prefer to use swap rates instead of treasury rates as the latter may be

\footnotetext{
7 Less than $2 \%$ of the observations in each year are based on prices before July. We repeated the empirical analysis with yields measured as the median over the second quarter with little effect on the results.
} 
artificially depressed during and after the crisis. ${ }^{8}$ We use bond spreads rather than CDS spreads because the market for CDS contracts is much more liquid than the secondary market for corporate bonds. Hence, it follows that CDS spreads mainly reflect default risk while credit spreads additionally incorporate a liquidity premium (see Longstaff, Mithal, and Neis (2005)). Since we are interested in understanding the evolution of risk preferences for different risk factors, bond spreads are more relevant to this study. Finally, there is lack of clarity on how illiquidity in the CDS market affects CDS spreads. For instance, according the Bongaerts, De Jong, and Driessen (2011), not the investors but the sellers of CDS contracts gain the liquidity premium. ${ }^{9}$

As default is directly related to a company's ability to fulfill its financial commitments, a number of financial ratios have been used in the literature to proxy for the likelihood of default of a company. We follow Blume, Keim, and Patel (1991) and Campbell and Taksler (2003) and use the following four ratios to measure credit risk: Long-Term Debt to Total Assets (LD/TA), Total Debt to Capitalization (TD/C), Pre-Tax Interest Coverage (IC), and Operating Income to Total Sales (OI/S). Also, based on the results of the comprehensive study by Bharath and Shumway (2008), we include a company's expected default frequency (EDF) from the Merton model, it's asset volatility $\left(\sigma_{A}\right)$, and the total firm value (in $\operatorname{logs}, \log (F V)$ ). To proxy for the liquidity of a bond, we use the Amihud (2002) measure of illiquidity (IL) and the effective bid-ask spread (EBA) of Roll (1984). Appendix A presents the construction of the factors in detail. All bonds with AAA rating or a rating below $\mathrm{B}$ are excluded since there are insufficient observations for these categories. We use rating dummies for each rating category and industry dummies based on the two-digit GIC codes. ${ }^{10}$

Table 1 presents summary statistics for our sample. Although we can only cover a relatively short time frame the sample contains a similar dispersion as other papers that use similar data (e.g., Campbell and Taksler (2003); Chen, Lesmond, and Wei (2007)). The average yield spread in our sample is $184 \mathrm{bps}$ with a standard deviation of $176 \mathrm{bps}$. The spread at the first decile is $25 \mathrm{bps}$ and $429 \mathrm{bps}$ at the top decile, which indicates that most of the observations lie in a moderate range. The average time to maturity in our sample is about 11 years and our sample is roughly evenly distributed among long-, medium-, and short-term bonds. The volatility of the asset value of the companies in the sample is on average $29.6 \%$ and ranges from $14 \%$ at the first decile to $52 \%$ at the top decile. The estimated expected default frequency (over a horizon of one year) is 0 for most companies. The $75 \%$ quantile value is $0.01 \%$ while the $90 \%$ quantile is $9 \%$ and the average

\footnotetext{
8 We also performed the analysis using credit spreads relative to treasury yields. The results are similar, but the estimated effect due to the intercept and the bond characteristics in the sequential decomposition (Section 5.3) are much larger since the resulting larger spreads cannot be explained with the risk factors of the regression.

9 Because of the issues arising from out-dated price information on bonds, an earlier version of this paper also used CDS spreads for the analysis. Because CDS data restricts the sample to firms for which CDS contracts are traded, we found it difficult to collect data for a sufficient amount of companies to perform inference on the counterfactual distributions.

10 It could be argued that the filters we apply bias our sample towards liquid bonds (see Friewald, Jankowitsch, and Subrahmanyam (2012)). If biased, our estimates for liquidity effects should be conservative as illiquidity effects should be even more pronounced for less liquid bonds.
} 
Table 1 Summary Statistics for Full Sample

\begin{tabular}{lrrrrrrr}
\hline & Mean & Q10 & Q25 & Median & Q75 & Q90 & Stdev \\
\hline & & & & & & & \\
Spread & 183.85 & 25.34 & 59.93 & 133.69 & 240.83 & 428.91 & 176.22 \\
Age & 5.23 & 0.69 & 1.77 & 3.86 & 7.81 & 12.01 & 4.51 \\
$C$ & 6.40 & 4.55 & 5.40 & 6.40 & 7.38 & 8.25 & 1.59 \\
$\tau$ & 10.89 & 1.96 & 3.87 & 7.30 & 15.64 & 26.29 & 11.23 \\
$I L$ & 0.17 & 0.00 & 0.00 & 0.05 & 0.20 & 0.47 & 0.31 \\
$E B A$ & 1.51 & 0.50 & 0.81 & 1.29 & 1.92 & 2.79 & 1.01 \\
$\sigma_{A}(\%)$ & 29.58 & 14.16 & 18.26 & 24.82 & 33.81 & 51.88 & 18.45 \\
$\log (F V)$ & 9.54 & 7.89 & 8.72 & 9.67 & 10.38 & 10.93 & 1.22 \\
$I C$ & 8.69 & 2.59 & 3.99 & 6.44 & 11.02 & 16.77 & 8.79 \\
$L D \backslash T A$ & 0.27 & 0.14 & 0.18 & 0.25 & 0.34 & 0.43 & 0.13 \\
$O I \backslash S$ & 0.20 & 0.06 & 0.10 & 0.16 & 0.27 & 0.38 & 0.16 \\
$T D \backslash C$ & 0.23 & 0.09 & 0.13 & 0.19 & 0.30 & 0.42 & 0.13 \\
$E D F(\%)$ & 5.67 & 0.00 & 0.00 & 0.00 & 0.01 & 9.04 & 19.13 \\
& & & & & & & \\
\hline
\end{tabular}

The data sample comprises all fixed-rate corporate bonds without special features from TRACE in the period October 2004 until June 2011 for which we were able to match the corresponding accounting data from Compustat and equity data in CRSP. Each variable is measured annually as of July $1^{\text {st }}$. Spread is the difference between the yield to maturity and the interpolated swap rate measured in basis points. Age is the time since the bond was first sold, $C$ is the (fixed) coupon rate, and $\tau$ is the time to maturity. $I L$ is the trade impact measure of Amihud (multiplied by a million). $E B A$ is the measure of the effective bid-ask spread. $\sigma_{A}$ is the volatility of the asset value and $\log (F V)$ is the $\log$ of the total asset value of the firm. $I C$ is the pre-tax interest coverage, $L D \backslash T A$ the ratio of long-term debt to total assets, $O I \backslash S$ is operating income to sales, and $T D \backslash C$ is total debt to capitalization. EDF is the Merton expected default frequency. Details on the variables can be found in Appendix A.

value is $5.7 \%$. Hence, most companies in the sample are not expected to default in the near future.

As we are mainly concerned with detecting differences in valuation before and after the crisis, we break down the sample into three period labeled pre-crisis (2005-07), crisis (2008-2009), and post-crisis (2010-2011). As our yearly observations are measured in the middle of the year, the first crisis year is 2008. Section 5.4 applies robustness tests to control for the sensitivity with respect to the choice of dates. Summary statistics by period are shown in Table 2. The data shows that spreads more than doubled during the crisis at each reported quantile. Comparing the pre-crisis and post-crisis levels of credit spreads we find that spreads have increased substantially. For the left-tail of the distribution, they have almost returned to their original levels. At the first, second, and third quartile spreads have increased by $48.3 \mathrm{bps}, 88.6 \mathrm{bps}$, and 125.1 , respectively, and at the $90 \%$-quantile the increase is 212.5 bps. The average spread has increased by $97.1 \mathrm{bps}$. At the same time, we observe that default related risk factors increase during the crisis. In particular EDF and asset volatility increase dramatically during the crisis but fall back to their original levels after. The pattern for measures of liquidity on the other hand is that they increase during the crisis and remain higher in the time after. These patterns suggest that investors' 
perception of the implications of different sources of risk may also have changed in differing ways. We will return to this question in the sequential decomposition in Section 5.3. 


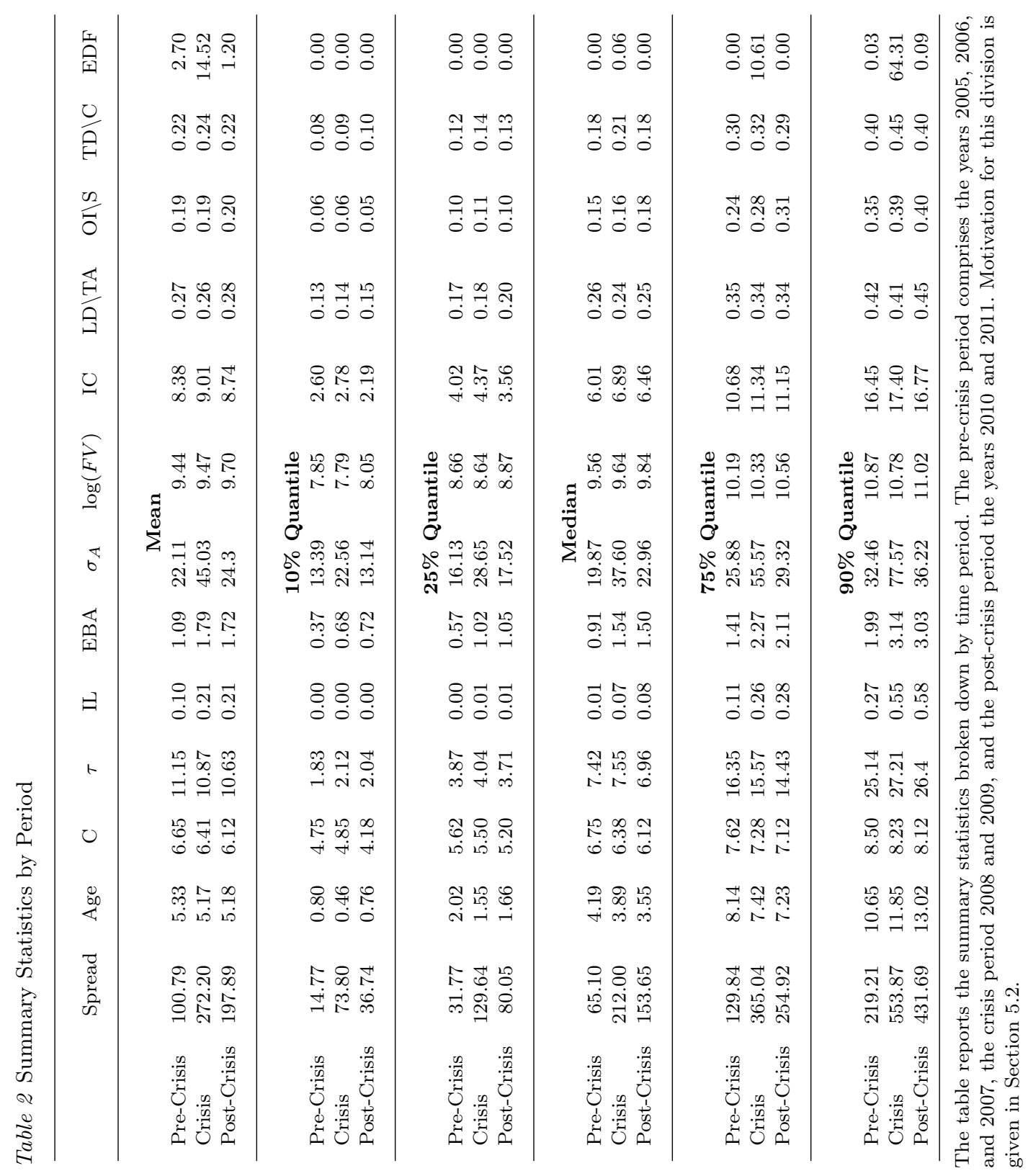




\section{Methodology}

Previous literature has focused on the explanatory power of specific risk factors on the cross-section of credit spreads. We build on that literature to explain the levels of credit spreads at one particular point in time. Our primary interest, however, is not to explain the level of credit spreads or even how they change over time. Rather, we are interested in attributing the change in credit spreads over time to changes in risk factors and changes in the pricing of these factors. Such questions are commonly addressed using regression based decomposition methods (see Fortin, Lemieux, and Firpo (2011) for a comprehensive survey of decomposition methods). For our question of interest, this method is a natural choice as we seek to understand the changes between two distinct points in time. In addition, this method allows us to use common regression techniques making the estimated results comparable to the empirical literature reviewed in Section 2. and allows us to attribute the changes to different types of risk factors. Thus, we do not require a structural model of the determination of credit spreads in order to estimate how the pricing of bonds has changed. An important limitation of this choice is that we cannot give explanations as to the economic mechanisms of the changes.

Our decomposition involves estimating the (counterfactual) distribution of credit spreads after the crisis that would have been observed if the mapping between risk factors and credit spreads had not been affected by the crisis (i.e., pricing of risk had remained the same). By comparing the counterfactual distribution to the observed distributions of bond spreads after the crisis we obtain an estimate of how much of the total change is due to changes in the pricing of risk factors. We use quantile regressions to estimate the mapping between risk factors to credit spreads, i.e. we assume that

$$
q\left(y^{t}, p ; \mathbf{X}^{\mathbf{t}}\right)=\boldsymbol{\beta} \mathbf{X}^{\mathbf{t}}+\boldsymbol{\epsilon}^{\boldsymbol{t}},
$$

where $q\left(y^{t}, p ; \mathbf{X}^{\mathbf{t}}\right)$ denotes the $p$ quantile of the distribution of credit spreads $y_{t}$ at time $t, \mathbf{X}^{\mathbf{t}}$ are the priced factors, and $\boldsymbol{\epsilon}^{\boldsymbol{t}}$ is an additive error term. Therefore, we assume that the relationship is linear in the coefficients in each quantile. Although this is somewhat restrictive, the initial estimation results in Section 5.1 show that much of the cross-sectional variation in credit spreads can be captured in this framework.

The papers by Pan and Singleton (2008) and Longstaff, Pan, Pedersen, and Singleton (2011) similarly estimate risk premia in credit spreads. The risk premium is derived as the difference between a model CDS spread and a "pseudo-spread" derived by setting the market price of risk to zero. The difference between these two estimates is the risk premium for credit events. This risk premium is then regressed on a set of explanatory variables to determine which factors drive default risk premia. As a result, the authors show which macroeconomic factors can explain the variation in default risk premiums. However, they cannot show how the pricing of specific risk factors changes by explicitly separating the impact from the realization of the risk factors. As we are interested in understanding how the risk pricing changed over time, their approach is unsuitable for our investigation. This methodology relies on a complete term structure of CDS spreads. In contrast to the market for sovereign CDSs investigated in their papers, the market for corporate CDSs at maturities other than the standard five year contract generally trade at very low liquidity levels. Hence, the methodology likely would yield inaccurate results. Also, CDSs are mostly traded only for large companies which would skew the sample and make results less general. Moreover, their methodology is parametric in nature as a specific form for the intensity of credit events under the objective measure and a functional form for the market price of 
risk has to be assumed. In addition, the two step approach induces a measurement error problem which inhibits the ability to estimate the relationship between credit spreads and risk factors precisely, i.e. the estimated variances are too large. Decomposition methods are developed to circumvent precisely this problem. And finally, we are interested in the individual effects that different risk factors have on total credit spreads rather than the effects on changes in the risk premia. Our paper shares with Pan and Singleton (2008) the interpretation that changes in the market price of risk is responsible for much of the variation in credit spreads.

To formally introduce the decomposition method, let $\mathbf{Y}^{t}$ be the variable of interest (i.e., the level of credit spreads at time $t$ ) and $\mathbf{X}^{t}$ be the set of explanatory variables at times $t \in\{0,1\}$ (i.e., the risk factors used to explain credit spread levels). The total observable change in credit spreads over time is then $\mathbf{Y}^{1}-\mathbf{Y}^{0}$. Let the conditional distribution of $\mathbf{Y}^{t}$ given $\mathbf{X}^{s}$ be denoted by $F_{\mathbf{Y}^{t} \mid \mathbf{X}^{s}}$. The estimated conditional distributions at times 0 and 1 are then $F_{\mathbf{Y}^{0} \mid \mathbf{X}^{0}}$ and $F_{\mathbf{Y}^{1} \mid \mathbf{X}^{1}}$. The distribution that we need to estimate is the distribution that would have resulted if only risk factors had changed (i.e., the marginal distribution of $\mathbf{X})$ but not the conditional distribution of bond spreads given the risk factors. We denote this by $F_{\mathbf{Y}(1,0)}$. It is constructed by integrating the conditional distribution of bond spreads at time $t=0$ with respect to the distribution of risk factors at time $t=1$ :

$$
F_{\mathbf{Y}(1,0)}(y)=\int F_{\mathbf{Y}^{0} \mid \mathbf{X}^{0}}(y \mid x) d F_{X^{1}}(x) .
$$

The difference between $F_{\mathbf{Y}(1,0)}$ and $\mathbf{Y}^{0}$ is the change in bond spreads resulting from changes in risk factors. The difference between $\mathbf{Y}^{1}$ and $q=F_{\mathbf{Y}(1,0)}^{-1}$ is the change resulting from changes in risk perception. This identifies how much of the change in the general level of credit spreads is solely caused by changes in the pricing implications of these risk factors. ${ }^{11}$

In order to construct a valid counterfactual distribution for a variable of interest, the following four assumptions have to be met.

Assumption 1 Mutually Exclusive Groups. The population of y can be divided into two mutually exclusive groups, denoted by group 0 and 1 .

As a bond is never traded at two different points in time simultaneously, this assumption is naturally met in our application.

Assumption 2 Structural Form. Elements $i$ of either group 0 or 1 have a mapping from factors $\left(\mathbf{X}^{\mathbf{t}}\right)$ to bond spreads $\left(y^{t}\right)$ which are functions depending on the observables $\mathbf{X}^{\mathbf{t}}$ and unobservables $\left(\boldsymbol{\epsilon}^{\boldsymbol{t}}\right)$ :

$$
y_{i}^{t}=m_{t}\left(\mathbf{X}_{\mathbf{i}}^{\mathbf{t}}, \epsilon_{i}\right),
$$

where $\epsilon_{i}$ has conditional distribution $F_{\epsilon \mid \mathbf{X}}$.

11 One concern with decomposition is the question whether the change in distributions could be due to omitted variables or unobserved characteristics. As discussed in Fortin, Lemieux, and Firpo (2011), the decomposition results are valid as long as their influence on the distribution of bond spreads is the same in both time periods. 
This amounts to assuming that the differences in credit spreads at each time period can only come from three distinct sources: Either differences in the function $m_{t}$, the observables $\mathbf{X}^{\mathbf{t}}$, or the unobservables $\epsilon$. The goal of decomposition analysis is to separate the effect of changes in $m_{t}$ from the other two.

Assumption 3 Simple Counterfactual Treatment. The estimated counterfactual distribution of credit spreads takes the same functional form as the functional form in the observed groups.

This assumption rules out general equilibrium effects which cannot be estimated using the partial equilibrium approach of the regression framework. Hence, we must assume that also in a world in which the financial crisis had not occurred, the linear quantile specification of credit spreads would have been a good representation of the cross-sectional differences in credit spreads.

Assumption 4 Overlapping Support. Let the support of all credit spread setting factors $[\mathbf{X}, \boldsymbol{\epsilon}]$ be $\boldsymbol{\chi} \times \mathbf{E}$. For all elements $[X, \epsilon]$ in $\boldsymbol{\chi} \times \mathbf{E}$, we have $0<\operatorname{Pr}[i \in$ group $1 \mid \mathbf{X}=X, \boldsymbol{\epsilon}=$ $\epsilon]<1$.

This assumption requires that for any bond, its combination of risk factors and unobservable characteristic does not enable us to clearly identify that it belongs to group 0 or 1 . This assumption would be violated if certain values of risk factors could only be observed before or after the crisis or if specific risk factors were only priced before or after. As this is not the case in the corporate bond market, the assumption is clearly met.

Another common assumption that usually has to be imposed is the following:

Assumption 5 Conditional Independence/Ignorability. For $t=0,1$, let the random variables $\left(\mathbf{1}_{t}(i), X, \epsilon\right)$ have a joint distribution. For all $x$ in $\boldsymbol{\chi}, \epsilon$ is independent of $\mathbf{1}_{t}(i)$ given $X=x$.

This assumption requires that the distribution of unobservables given the risk factors $X$ is the same at both points in time. As we do not expect this assumption to be met in the case of corporate credit spreads, we also estimate the separate effect that changes in the distribution of residuals have had on credit spreads using the results in Melly (2006) and Chernozhukov, Fernández-Val, and Melly (2013). This choice comes at the cost that we are not able to perform a detailed decomposition for the risk factors. Hence, we can only estimate the entire effect of the change in risk factors, but we cannot estimate the effect that changes in specific variables have had. As we are mainly interested in the change in risk pricing, i.e. changes in the coefficients, we do not consider this to be a limitation for addressing the research question at hand.

We use both standard and quantile regressions to model the relationship $F_{\mathbf{Y}^{t} \mid \mathbf{X}^{t}}$ between risk factors $\mathbf{X}^{t}$ and credit spreads $\mathbf{Y}^{t}$. However, we favor the later specification since it allows us to control for non-linearity in the pricing relationship of risk factors. For instance, one would expect that liquidity risk has different implications for highyield bonds than for low-yield bonds. Quantile regression can detect these differences in a natural way without any ad-hoc adjustments to the sample (such as splitting the sample by credit ratings). To be precise, we estimate the $p^{\text {th }}$ unconditional quantile function at 
time $t$ as

$$
\hat{F}^{-1}\left(p ; \hat{\boldsymbol{\beta}}, \mathbf{X}^{t}\right)=\hat{q}\left(p ; \hat{\boldsymbol{\beta}}, \mathbf{X}^{t}\right)=\inf \left\{q: \frac{1}{N} \sum_{i=1}^{N} \sum_{j=1}^{J} \mathbf{1}\left(\mathbf{X}_{i}^{t} \cdot \hat{\boldsymbol{\beta}}\left(p_{j}\right) \leq q\right) \geq p\right\},
$$

where $J$ denotes the number of estimated quantiles and $\mathbf{1}(\cdot)$ is the indicator function.

For the estimation of the counterfactual distribution, we build on the work by Melly (2005) and Chernozhukov, Fernández-Val, and Melly (2013). ${ }^{12}$ The distribution of bond spreads that would have resulted if no adjustment to pricing had taken place is estimated by combining the marginal distribution of the risk factors after the crisis with the pricing before the crisis. This is done by inserting the covariates $\mathbf{X}^{1}$ from the post-crisis period 1 and the estimated coefficients $\boldsymbol{\beta}^{0}$ from the pre-crisis period 0 in (6):

$$
\hat{q}\left(p ; \boldsymbol{\beta}^{0}, \mathbf{X}^{1}\right)=\inf \left\{q: \frac{1}{N_{0}} \sum_{i=1}^{N_{1}} \sum_{j=1}^{J} \mathbf{1}\left(\mathbf{X}_{i}^{1} \cdot \hat{\boldsymbol{\beta}}^{0}\left(p_{j}\right) \leq q\right) \geq p\right\}
$$

where $N_{t}$ is the number of observations in period $t$. Hence, the change due to changes in the risk factors is $\hat{q}\left(\boldsymbol{\beta}^{0}, \mathbf{X}^{1}\right)-q^{0}$. The remainder of the total change, $q^{1}-\hat{q}\left(\boldsymbol{\beta}^{0}, \mathbf{X}^{1}\right)$, can be interpreted as time-varying pricing of risk resulting from changes in risk perception.

We further decompose this in order to account for variation in spreads that cannot be explained by our model, i.e. changes in the distribution of residuals. The resulting distribution, denoted by $\hat{q}\left(\boldsymbol{\beta}_{r_{0}}^{1}, \mathbf{X}^{1}\right)$, is the distribution that would have prevailed if risk factors and risk pricing had changed as it has but the distribution of residuals had remained the same. Thereby, $\boldsymbol{\beta}_{r_{0}}^{1}$ refers to the estimates of the coefficients at the median at time 1 while using the residuals at time 0 . Melly (2005) notes that $\mathbf{X}(\hat{\boldsymbol{\beta}}(p)-\hat{\boldsymbol{\beta}}(0.5))$ is a consistent estimator of the $p^{\text {th }}$ quantile of the residual distribution conditional on $\mathbf{X}$. Hence, we define $\boldsymbol{\beta}_{r_{0}}^{1}(p)=\hat{\boldsymbol{\beta}}^{1}(0.5)+\hat{\boldsymbol{\beta}}^{0}(p)-\hat{\boldsymbol{\beta}}^{0}(0.5)$ which are then plugged into (7) instead of $\boldsymbol{\beta}^{0}$. This step separates the effect changes in risk pricing (i.e., the coefficients of the covariates) have from effects that arise from residuals.

To sum up, the observed change over time, $q_{1}-q_{0}$ is decomposed into three components:

$$
\underbrace{q^{1}-q^{0}}_{\text {Observed Change }}=\underbrace{\left[\hat{q}\left(\boldsymbol{\beta}^{0}, \mathbf{X}^{1}\right)-q^{0}\right]}_{\text {Change in Risk Factors }}+\underbrace{\left[\hat{q}\left(\boldsymbol{\beta}_{r_{0}}^{1}, \mathbf{X}^{1}\right)-\hat{q}\left(\boldsymbol{\beta}^{0}, \mathbf{X}^{1}\right)\right]}_{\text {Change in Pricing }}+\underbrace{\left[q^{1}-\hat{q}\left(\boldsymbol{\beta}_{r_{0}}^{1}, \mathbf{X}^{1}\right)\right]}_{\text {Change in Residuals }},
$$

where, for simplicity, we have suppressed the dependence on the quantile $p$. The first component adjusts for the effect that changes in the marginal distribution of the risk factors has had. The second component is the effect that changes in risk pricing had on bond spreads. We interpret this component as structural change as it represents a direct estimate of how investors have updated their risk perception over the course of the financial crisis. The final component represents an estimate of the variation in credit spreads that is not captured by our model. Hence, Equation (8) can be interpreted along

12 The methodology of using quantile regression to perform counterfactual analysis originated in Machado and Mata (2005) and Gosling, Machin, and Meghir (2000) which is an extension of the Oaxaca-Blinder decomposition technique for differences at the mean (Oaxaca, 1973; Blinder, 1973). The recent paper by Chernozhukov, Fernández-Val, and Melly (2013) significantly extends this literature and also develops formal inference procedure. 
the lines of Equation (2). The first two terms in (8) refer to changes in the state variables that determine the default arrival and cost of illiquidity processes and changes in the market price of risk, respectively. The decomposition methodology is used to disentangle and quantify the contribution of each to the observed changes in credit spreads on the left hand side of (8).

The decomposition so far only isolates the aggregate effect that the crisis had. Most economists would agree that in particular liquidity risk was re-evaluated by market participants during the crisis (see, e.g., Berger and Bouwman (2009); Brunnermeier (2009); Guiso, Sapienza, and Zingales (2013)). To estimate the separate contributions of risk perception towards default and liquidity, we estimate a sequence of counterfactual distributions by incrementally updating the conditional distributions of the covariates. We follow the sequential approach suggested in Antonczyk, Fitzenberger, and Sommerfeld (2010) but explicitly account for the residual effect as described in (8). Let $\hat{q}\left(\hat{\boldsymbol{\beta}}^{D_{t}, L_{t}, B_{t}, I_{t}}, \mathbf{X}^{t}\right)$ denote the estimated counterfactual quantiles of credit spreads with covariates $\mathbf{X}^{t}$ and

$$
\hat{\boldsymbol{\beta}}^{D_{t}, L_{t}, B_{t}, I_{t}}=\hat{\boldsymbol{\beta}}^{D_{t}, L_{t}, B_{t}, I_{t}}(0.5)+\hat{\boldsymbol{\beta}}^{0}(p)-\hat{\boldsymbol{\beta}}^{0}(0.5),
$$

where $\hat{\boldsymbol{\beta}}^{D_{t}, L_{t}, B_{t}, I_{t}}$ denotes the vector of coefficients related to default risk $\left(D_{t}\right)$, liquidity risk $\left(L_{t}\right)$, bond characteristics $\left(B_{t}\right)$, and intercept $\left(I_{t}\right)$ from period $t{ }^{13}$

First, we account for the general level shift from the intercept by estimating $\Delta^{\text {Intercept }}=\hat{q}\left(\hat{\boldsymbol{\beta}}^{D_{0}, L_{0}, B_{0}, I_{1}}, \mathbf{X}^{1}\right)-\hat{q}\left(\hat{\boldsymbol{\beta}}^{D_{0}, L_{0}, B_{0}, I_{0}}, \mathbf{X}^{1}\right)$. This effect contains the changes in macroeconomic conditions for which we cannot control for in our cross-sectional regression and counterfactual decomposition framework. Next, we adjust for changes in the pricing of default risk $\Delta^{\text {Default }}=\hat{q}\left(\hat{\boldsymbol{\beta}}^{D_{1}, L_{0}, B_{0}, I_{0}}, \mathbf{X}^{1}\right)-\hat{q}\left(\hat{\boldsymbol{\beta}}^{D_{0}, L_{0}, B_{0}, I_{0}}, \mathbf{X}^{1}\right)$. This difference is a direct estimate of how changes in risk pricing of default have altered the levels of credit spreads observed on the market. In a similar fashion, we then update the effect of liquidity risk pricing by estimating $\Delta^{\text {Liquidity }}=\hat{q}\left(\hat{\boldsymbol{\beta}}^{D_{1}, L_{1}, B_{0}, I_{0}}, \mathbf{X}^{1}\right)-\hat{q}\left(\hat{\boldsymbol{\beta}}^{D_{1}, L_{0}, B_{0}, I_{0}}, \mathbf{X}^{1}\right)$. This change estimates the effect of changes in the pricing of liquidity risk, holding fixed the influence of other common risk factors. Finally, we account for the change in the pricing of indenture data by estimating $\Delta^{\text {Bond Char. }}=\hat{q}\left(\hat{\boldsymbol{\beta}}^{D_{1}, L_{1}, B_{1}, I_{0}}, \mathbf{X}^{1}\right)-\hat{q}\left(\hat{\boldsymbol{\beta}}^{D_{1}, L_{1}, B_{0}, I_{0}}, \mathbf{X}^{1}\right)$. The remaining difference, $q^{1}-\hat{q}\left(\hat{\boldsymbol{\beta}}^{D_{1}, L_{1}, B_{1}, I_{1}}, \mathbf{X}^{1}\right)$ is then the residual effect that is not captured by our model. The total decomposition ${ }^{14}$ can be summarized as follows:

$$
\begin{aligned}
& \underbrace{q^{1}-q^{0}}_{\text {Observed Change }}=\underbrace{\left[\hat{q}\left(\hat{\boldsymbol{\beta}}^{D_{0}, L_{0}, B_{0}, I_{0}}, \mathbf{X}^{1}\right)-q^{0}\right]}_{\text {Change in Risk Factors }} \\
&+\underbrace{\Delta^{\text {Intercept }}+\Delta^{\text {Default }}+\Delta^{\text {Liquidity }}+\Delta^{\text {Bond Char. }}}_{\text {Change in Pricing }} . \\
&+\underbrace{\left[q^{1}-\hat{q}\left(\hat{\boldsymbol{\beta}}^{D_{1}, L_{1}, B_{1}, I_{1}}, \mathbf{X}^{1}\right)\right]}_{\text {Change in Residuals }} .
\end{aligned}
$$

\footnotetext{
$\overline{13}$ Bond characteristics are variables related to indenture data: age, the coupon rate and maturity.

14 It should be noted that, in general, results depend on the sequence of the decomposition. We tried several other sequences with essentially equal results which are available from the authors upon request.
} 
The decomposition essentially entails plugging in different estimates for the coefficients in the representation in (6). The results of these decomposition should be interpreted as the difference in the risk premium associated with a particular risk at a given quantile of the distribution of credit spreads holding the level of the risk factor constant. Therefore, a quantile effect of 10 bps at a given quantile would imply that markets attach a $10 \mathrm{bps}$ higher premium for that risk at that quantile. We interpret this as the result of altered risk perception on markets.

An implicit assumption of this methodology is that credit spreads are stationary in quantiles. In this paper, this means that the riskiness implied by the spread of a bond depends on its relative not absolute size. For example, a $100 \mathrm{bps}$ spread may indicate a safe or risky bond at different time periods. On the other hand, a bond with a spread at the 10th percentile of the overall distribution implies the same level of riskiness at all time periods. We explicitly control for this potential bias by providing the decomposition results using OLS estimation at the mean, conducting a qualitative analysis of quantile jumps, and re-estimate the models by only including firms which are permanently available in our entire sample (see robustness check in Section refsec:robust). All three tests confirm that the results are not affected by severe quantile jumps.

\section{Pricing of Bond Spreads}

\subsection{Regression Results}

We use the following specification in order to test our hypotheses and to explain the observed levels of credit spreads:

$$
\begin{gathered}
\text { Spread }=\alpha+\underbrace{\beta_{1} \text { Age }+\beta_{2} \mathrm{C}+\beta_{3} \tau}_{\text {Bond Characteristics }}+\underbrace{\beta_{4} \mathrm{IL}+\beta_{5} \text { EBA }}_{\text {Liquidity Risk }} \\
+\underbrace{\beta_{6} \sigma_{A}+\beta_{7} \log (\text { Firm Value })+\beta_{8} \mathrm{IC}+\beta_{9} \mathrm{LD} \backslash \mathrm{TA}+\beta_{10} \mathrm{OI} \backslash \mathrm{S}+\beta_{11} \mathrm{TD} \backslash \mathrm{C}}_{\text {Default Risk }} \\
+\underbrace{\beta_{12} \mathrm{EDF}+\beta_{13} \text { Rating Dummy }}_{\text {Default Risk }}+\beta_{14} \text { Industry Dummy }+\beta_{15} \text { Year Dummy }+\varepsilon .
\end{gathered}
$$

We group the covariates into three categories. Bond characteristics contain all variables which are directly related to the bond in question. The other two groups are variables directly related to liquidity and default risk, respectively. To control for time-varying influences, such as changes in the macroeconomic environment, we add time-fixed effects and industry dummies. The bond characteristics included are frequently associated with the liquidity of a bond. Hence, one could also include these variables as measures of liquidity.

In order to use the linear regression (10) for the counterfactual experiment it needs to be able to explain the cross-section of bond spreads sufficiently well. The results based on OLS regression for the full sample is presented in the first column of Table 3. Since most covariates are highly skewed the quantitative value of the OLS estimates needs to be evaluated carefully. Later, we employ quantile regression for which departure from normality of the regressors is less of an issue. We generally find that the coefficients have the expected signs and most coefficients are significant. Both measures of illiquidity increase spreads and are statistically highly significant. For the default variables, higher asset 
volatility, debt to capital, and expected default frequency are all associated with higher spreads, whereas the interest coverage and operating income lower spreads; although the former is not significant. Long-term debt to total assets has a negative and statistically significant coefficient. The adjusted $R^{2}$ of the OLS specification is $70 \%$ which indicates that regression (10) is indeed an appropriate description of bond spreads. Although some of the variables exhibit high correlations (see Table B.1 in Appendix B) variance inflation factors (unreported) are all below five. Hence, multicollinearity does not seem to be affecting the estimation results.

In order to examine the marginal explanatory power of the various risk categories we consecutively exclude them from the set of regressors. To conserve space, we report the full table in Table C.1 in the Appendix. We chose to report results in this way as opposed to simply regressing the subset of factors and excluding all others as results in this format might be subject to an omitted variable bias. The regressions which omit a class of regressors have similar explanatory power as measured by the adjusted $R^{2}$ statistic which range from $63 \%$ to $69 \%$ and are thus only slightly lower than the adjusted $R^{2}$ of the full specification. A log-likelihood test rejects the restricted models in favor of the unrestricted one in each case. This indicates that all risk categories are necessary to provide a complete picture of the components of credit spreads. Most estimates have similar magnitude and significance across all regression specifications. The estimates for the rating dummies change substantially when default related variables are excluded and the adjusted $R^{2}$ decreases by $10 \%$. These results show that ratings and accounting ratios each contain information beyond what is implied by the other.

Previous studies have documented that the influence of risk factors changes as bonds become riskier. Rather than breaking our sample into rating groups, we perform quantile regressions. Several authors have noted that ratings are a crude measure of default risk and may not always reflect all information (see Hilscher and Wilson (2013)). Assuming reasonably efficient markets, the information contained in our covariates should be contained in the level of credit spreads. Therefore, should certain risk factors be more relevant for different types of bonds this should be reflected in the coefficient estimates along the quantiles of credit spreads. There is, of course, a strong relation between the level of credit spreads and bond ratings. In our sample, we find a rank correlation of 0.45 (based on Kendall's $\tau$ ) and 0.57 (based on Spearman's $\rho$ ) between ratings and spreads. In Figure 2 we report box plots for spreads by ratings. The figure shows that there is a strong correspondence of better ratings with lower spreads.

The results of the quantile regressions for the entire sample at selected quantiles are presented in Table 3. The quantile estimation results for our pre-crisis, crisis, and postcrisis sub-samples are reported in Appendix D. ${ }^{15}$ The pseudo $R^{2}$ of the quantile regressions increases from $31 \%$ at the first decile to $61 \%$ at the ninth decile with an $R^{2}$ of $53 \%$ at the median. For the median and OLS regression, the signs of the coefficients agree and their magnitudes are very similar. We conclude that both specifications provide a similar picture of the central tendency of how risk factors affect the level of credit spreads. Figure 3 provides the estimated quantile functions for all variables (excluding dummy variables).

According to the Wald test, proposed by Bassett and Koenker (1982), we find a significant quantile effect for most covariates (i.e., the coefficients in the $10 \%$ decile are

15 To save space we do not present results for individual years. Overall, these are very similar to the results for the respective sub-periods and available from the authors upon request. 
Table 3 Quantile Regression Results for Full Sample

\begin{tabular}{|c|c|c|c|c|c|}
\hline & OLS & $\mathrm{Q}(0.5)$ & $\mathrm{Q}(0.1)$ & $\mathrm{Q}(0.9)$ & $\mathrm{Q}(0.9)-\mathrm{Q}(0.1)$ \\
\hline Intercept & $\begin{array}{l}47.53^{* * *} \\
(2.80)\end{array}$ & $\begin{array}{l}17.27 \\
(1.17)\end{array}$ & $\begin{array}{l}-29.36 \\
(-1.52)\end{array}$ & $\begin{array}{c}170.21^{* * *} \\
(6.40)\end{array}$ & 199.57 \\
\hline Age & $\begin{array}{c}0.84^{* *} \\
(2.52)\end{array}$ & $\begin{array}{c}0.17 \\
(0.56)\end{array}$ & $\begin{array}{l}-2.17^{* * *} \\
(-6.01)\end{array}$ & $\begin{array}{l}1.45^{* * *} \\
(3.22)\end{array}$ & $\begin{array}{c}3.63^{* * *} \\
(106.40)\end{array}$ \\
\hline C & $\begin{array}{l}10.72^{* * *} \\
(11.53)\end{array}$ & $\begin{array}{l}11.55^{* * *} \\
(13.34)\end{array}$ & $\begin{array}{l}12.58^{* * *} \\
(11.77)\end{array}$ & $\begin{array}{l}8.43^{* * * *} \\
(5.97)\end{array}$ & $\begin{array}{l}-4.15^{* * *} \\
(12.82)\end{array}$ \\
\hline$\tau$ & $\begin{array}{c}1.36^{* * *} \\
(11.18)\end{array}$ & $\begin{array}{c}1.82^{* * *} \\
(19.25)\end{array}$ & $\begin{array}{c}1.47^{* * *} \\
(14.99)\end{array}$ & $\begin{array}{l}1.22^{* * *} \\
(7.08)\end{array}$ & $\begin{array}{c}-0.25^{* *} \\
(3.92)\end{array}$ \\
\hline$I L$ & $\begin{array}{l}10.59^{* *} \\
(2.31)\end{array}$ & $\begin{array}{l}16.13^{* * *} \\
(3.93)\end{array}$ & $\begin{array}{c}3.55 \\
(0.61)\end{array}$ & $\begin{array}{l}31.95^{* *} \\
(2.31)\end{array}$ & $\begin{array}{l}28.40^{* * *} \\
(7.55)\end{array}$ \\
\hline$E B A$ & $\begin{array}{l}17.28^{* * *} \\
(10.17)\end{array}$ & $\begin{array}{l}14.33^{* * *} \\
(9.24)\end{array}$ & $\begin{array}{l}17.52^{* * *} \\
(10.32)\end{array}$ & $\begin{array}{l}10.05^{* * *} \\
(4.13)\end{array}$ & $\begin{array}{l}-7.46^{* * *} \\
(13.32)\end{array}$ \\
\hline$\sigma_{A}$ & $\begin{array}{l}1.08^{* * *} \\
(9.89)\end{array}$ & $\begin{array}{c}1.45^{* * *} \\
(10.08)\end{array}$ & $\begin{array}{l}0.48^{* * *} \\
(5.56)\end{array}$ & $\begin{array}{l}1.96^{* * *} \\
(6.22)\end{array}$ & $\begin{array}{c}1.47^{* * *} \\
(43.50)\end{array}$ \\
\hline $\log (F V)$ & $\begin{array}{l}-18.02^{* * *} \\
(-12.61)\end{array}$ & $\begin{array}{l}-14.91^{* * *} \\
(-13.61)\end{array}$ & $\begin{array}{l}-9.07^{* * *} \\
(-5.51)\end{array}$ & $\begin{array}{l}-23.76^{* * *} \\
(-11.87)\end{array}$ & $\begin{array}{c}-14.68^{* * *} \\
(89.47)\end{array}$ \\
\hline$I C$ & $\begin{array}{l}-0.21 \\
(-1.18)\end{array}$ & $\begin{array}{c}-0.14 \\
(-1.24)\end{array}$ & $\begin{array}{c}-0.35^{*} \\
(-1.66)\end{array}$ & $\begin{array}{c}-0.51^{* *} \\
(-2.54)\end{array}$ & $\begin{array}{c}-0.16 \\
(0.81)\end{array}$ \\
\hline$L D \backslash T A$ & $\begin{array}{l}-35.76^{* *} \\
(-2.22)\end{array}$ & $\begin{array}{l}-43.75^{* * *} \\
(-2.92)\end{array}$ & $\begin{array}{l}-10.16 \\
(-0.60)\end{array}$ & $\begin{array}{l}-52.81^{* *} \\
(-2.04)\end{array}$ & $\begin{array}{c}-42.65^{* *} \\
(5.64)\end{array}$ \\
\hline$O I \backslash S$ & $\begin{array}{l}-38.00^{* * *} \\
(-3.99)\end{array}$ & $\begin{array}{l}-43.11^{* * *} \\
(-6.09)\end{array}$ & $\begin{array}{l}-30.40^{* *} \\
(-2.32)\end{array}$ & $\begin{array}{l}-23.52 \\
(-1.53)\end{array}$ & $\begin{array}{c}6.87 \\
(0.37)\end{array}$ \\
\hline$T D \backslash C$ & $\begin{array}{c}125.54^{* * *} \\
(6.18)\end{array}$ & $\begin{array}{c}147.31^{* * *} \\
(9.56)\end{array}$ & $\begin{array}{l}41.47^{* *} \\
(2.05)\end{array}$ & $\begin{array}{c}135.71^{* * *} \\
(3.36)\end{array}$ & $\begin{array}{l}94.23^{* * *} \\
(17.94)\end{array}$ \\
\hline$E D F$ & $\begin{array}{c}1.72^{* * *} \\
(18.41)\end{array}$ & $\begin{array}{c}1.94^{* * *} \\
(11.14)\end{array}$ & $\begin{array}{l}0.83^{* * *} \\
(4.21)\end{array}$ & $\begin{array}{c}3.15^{* * *} \\
(13.52)\end{array}$ & $\begin{array}{c}2.32^{* * *} \\
(50.82)\end{array}$ \\
\hline$R^{2}$ & 0.70 & 0.53 & 0.31 & 0.61 & \\
\hline
\end{tabular}

The table reports the coefficients from the regression in (10) for the full sample with $t$-values in parentheses. White (1980) standard errors are used. All regressions contain (unreported) rating, industry and year dummies. The first column contains the OLS results for comparison. Columns two to four are the quantile regression results at the median, the first decile, and the last decile, respectively. Standard errors in the quantile regressions are obtained by bootstrapping 500 times using the resampling method of Parzen, Wei, and Ying (1994). The final column reports the difference between the $9^{\text {th }}$ and $1^{\text {st }}$ decile. The values in parentheses are the $F$-statistic of the Wald test proposed by Bassett and Koenker (1982) to test for equality of coefficients. *** denotes significance at the $1 \%, * *$ at $5 \%$, and $*$ at $10 \%$ level.

significantly different from the coefficients in the $90 \%$ decile). For the coupon rate $(C)$, time to maturity $(\tau), E B A, \log (F V), L D \backslash T A$ there is a significant (at least at $10 \%$ level) negative quantile effect. We find a significant positive quantile effect for $A g e, I L, \sigma_{A}$, and $E D F$. Since we only test the first against the last decile, this test can only provide indication of a linear quantile function. The quantile functions in Figure 3 show that there is an inverse U-shaped relationship for $\tau$ and for $T D \backslash C$. For 10 out of the total of 12 


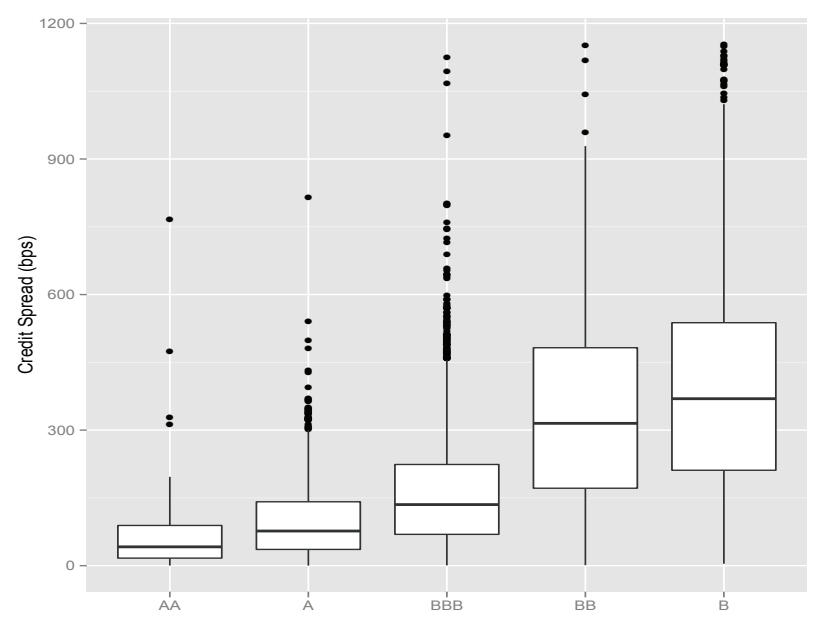

Fig. 2. Box-and-Whiskers Plot of Credit Spreads by Ratings. The chart shows Box-and-Whiskers plot for the spreads in the full sample by credit ratings. The solid black line indicates the median value and the box denotes the range of the $25 \%$ quantile to the $75 \%$ quantile. The Whiskers extend 1.5 times the interquartile range. Outliers beyond this point are indicated by black circles.

variables we find a significant quantile effect (at least at the $5 \%$ significance level). This indicates that the quantile regression is indeed more appropriate to analyze the effect of various risk factors on credit spreads. In addition, the quantile regression comes along with another advantage. It naturally accommodates non-linearity in the relationship between risk factors and credit spreads. This reduces potential biases on pricing effects that are associated with changes in factors levels when going from before to after the crisis period.

\subsection{What if the Financial Crisis had not Happened?}

The prior results indicate that the regression specification in (10) is able to capture a large fraction of the cross-sectional differences in credit spreads. Given these results, we now turn to the main question. Obviously, credit spreads after the crisis have remained at a higher level than they were before. The question is, what has caused this lasting increase in spreads? How much of the change is due to changes in the risk factors, i.e. changes in the composition of bonds and business climate, and how much of the change is due to changes in risk perception, i.e. a reevaluation by markets of what the risk implications of the determinants of credit spreads are? We use the decomposition approach discussed in Section 4. to generate the counterfactual distributions of interest. ${ }^{16}$ Thereby, we will

\footnotetext{
$\overline{16}$ A simple comparison of the OLS or QR coefficients in Appendix D leads qualitatively to the same conclusions in that the coefficients show a similar pattern as described below. Although much simpler, this method is unsatisfactory for two reasons. First, it cannot distinguish between the effect of changes in the factors themselves and the pure coefficient effect. Second, we are interested in quantifying these two types of effects separately. Hence,
} 


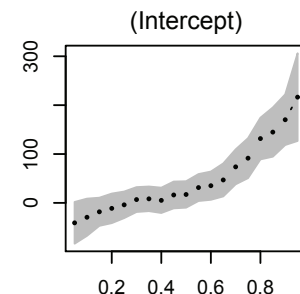

IL

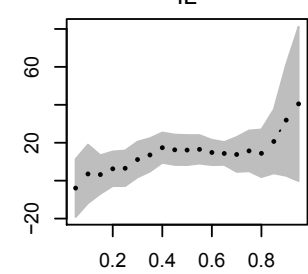

IC

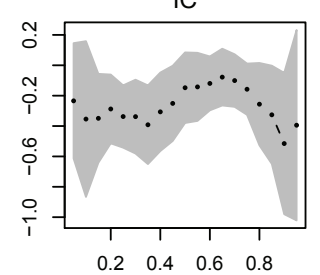

EDF

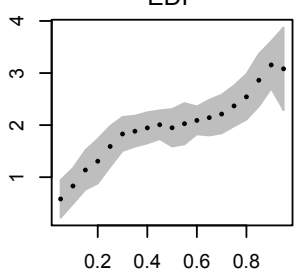

Age

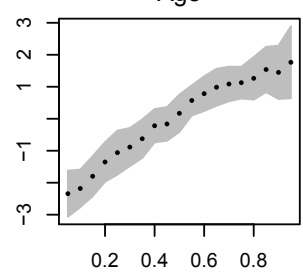

EBA

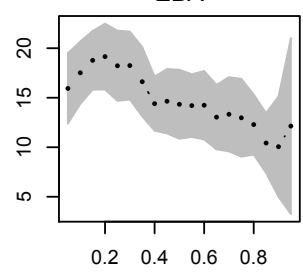

LDITA

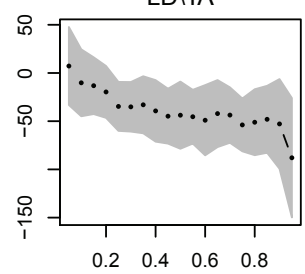

C

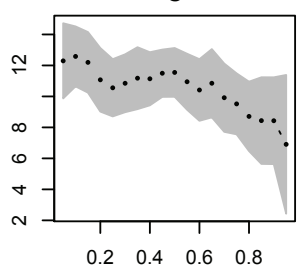

$\sigma_{\mathrm{A}}$

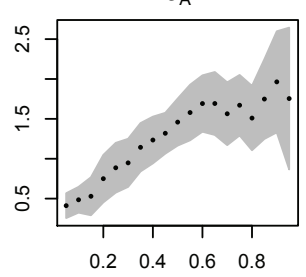

OIIS

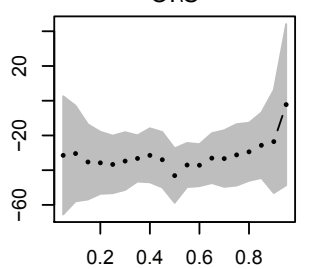

$\tau$

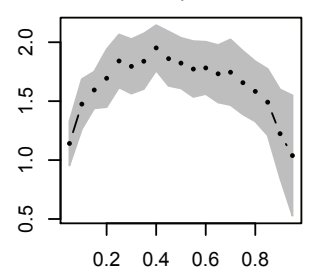

$\log (\mathrm{FV})$

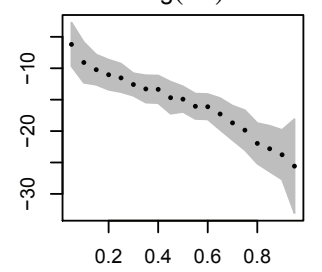

TDIC

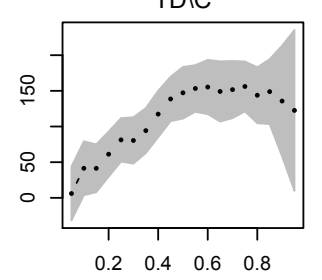

Fig. 3. Quantile Functions for Full Sample. The graphs plot the quantile function for the coefficient of each covariate (black dots) together with the $95 \%$ confidence band (gray area) obtained by bootstrapping 500 times using the resampling method of Parzen, Wei, and Ying (1994).

be mostly concerned with two questions: First, what would credit spreads look like if the financial crisis in late 2007 to early 2009 had not occurred? Second, what if risk perception and pricing of risk had remained at the levels that had prevailed before the crisis?

Figure 4 presents the distributions of credit spreads for each year of our sample. The distribution of credit spreads in the years 2005 to 2007 are approximately equal. By mid 2008, spreads along all quantiles have increased visibly. For 2009, there is a slight decrease in the upper quantiles (relative to 2008). The distributions for 2010 and 2011

it is preferable to illustrate the effects in terms of changes of credit spreads rather than changes in coefficients as this makes it easier to interpret the results economically. 


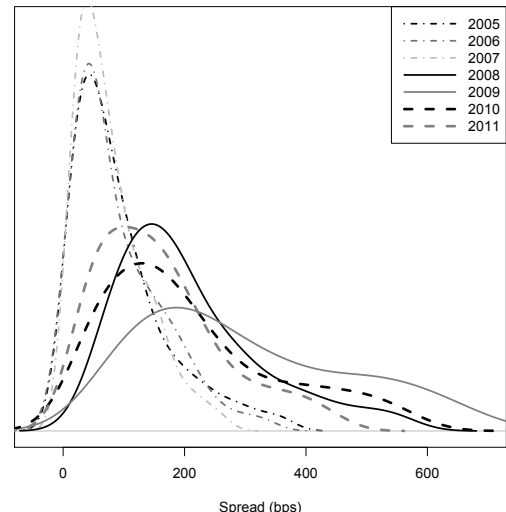

(a)

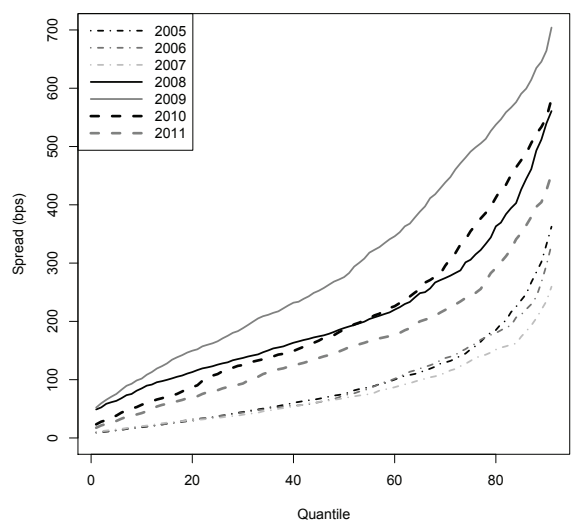

(b)

Fig. 4. Mid-Year Distributions of Credit Spreads (2005 - 2011). The Figure shows the empirical density (Panel (a)) and quantile function (Panel (b)) of credit spreads for each year in the sample.

are somewhat in the middle. To test more formally whether the distribution of credit spreads has materially changed over the years we use pairwise Kolmogorov-Smirnov tests. Results are reported in Table 4. We find that we cannot reject the null hypothesis of equal distributions for the pairs 2005-2006, 2005-2007, 2006-2007, and 2010-2011. Based on these results, we regard the sample from 2005-2007 as one period labeled pre-crisis, the sample from 2008-2009 as one period labeled crisis $^{17}$, and 2010-2011 as labeled post-crisis. One can argue that our post-crisis period also covers the economic recession in the US which may affect our results. However, if we assume that changes in the real economy have an impact on credit spreads then these effects should be reflected in changes in the risk factors and not in the pricing coefficients or risk perception, respectively.

The total change in the distribution of credit spreads over the different periods is shown in Figure 5. The graph clearly shows how spreads have increased over the crisis. During the crisis period, spreads at the first decile were 59 bps higher and 335 bps higher at the ninth decile. The increase at the median was 147 bps. After the crisis had ended, spreads decreased again (by $37 \mathrm{bps}$ at the first decile, $58 \mathrm{bps}$ at the median, and $122 \mathrm{bps}$ at the ninth decile). What can be clearly seen is that they have not returned to their initial level. For each of the three time steps we perform the decomposition into the component that is due to changes in risk factors and the component that is due to changes in risk perception, i.e. due to time-varying pricing of risk, described in Section 4.. The results are summarized in Figure 6. Appendices $\mathrm{E}$ and $\mathrm{F}$ report confidence bands in Figures E.1 to E.3 and detailed results on the estimates in Tables F.1, F.2, and F.3 for all three decompositions.

17 The Kolmogorov-Smirnov test rejects the null hypothesis of equal distributions for the pair 2008-2009. This is not of major relevance to the results since we are interested in the change in pricing between pre- and post-crisis period and the lasting increase in credit spreads due to a change in pricing of risk factors. 
Table 4 Results of Kolmogorov-Smirnov Tests for Equal Distributions

\begin{tabular}{ccccccc}
\hline & 2006 & 2007 & 2008 & 2009 & 2010 & 2011 \\
\hline \multirow{2}{*}{2005} & 0.05 & 0.08 & $0.46^{* * *}$ & $0.57^{* * *}$ & $0.40^{* * *}$ & $0.30^{* * *}$ \\
& $(1.00)$ & $(0.91)$ & $(0.00)$ & $(0.00)$ & $(0.00)$ & $(0.00)$ \\
2006 & & 0.08 & $0.46^{* * *}$ & $0.55^{* * *}$ & $0.38^{* * *}$ & $0.30^{* * *}$ \\
& & $(0.91)$ & $(0.00)$ & $(0.00)$ & $(0.00)$ & $(0.00)$ \\
2007 & & $0.52^{* * *}$ & $0.62^{* * *}$ & $0.45^{* * *}$ & $0.36^{* * *}$ \\
& & & $(0.00)$ & $(0.00)$ & $(0.00)$ & $(0.00)$ \\
2008 & & & $0.23^{* *}$ & 0.10 & $0.18^{*}$ \\
& & & $(0.01)$ & $(0.70)$ & $(0.08)$ \\
2009 & & & & $0.22^{* *}$ & $0.34^{* * *}$ \\
& & & & & $0.01)$ & $0.00)$ \\
2010 & & & & & & 0.13 \\
& & & & & & $0.36)$ \\
\end{tabular}

The table reports the test statistics of Kolmogorov-Smirnov tests for equality of the distribution of credit spreads for each pair of years in the sample. P-values are reported in parentheses. ${ }^{* * *}$ denotes significance at the $1 \%,{ }^{* *}$ at $5 \%$, and ${ }^{*}$ at $10 \%$ level.

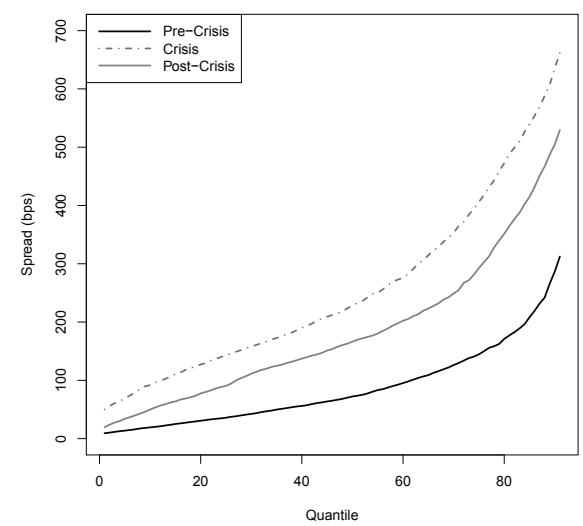

(a)

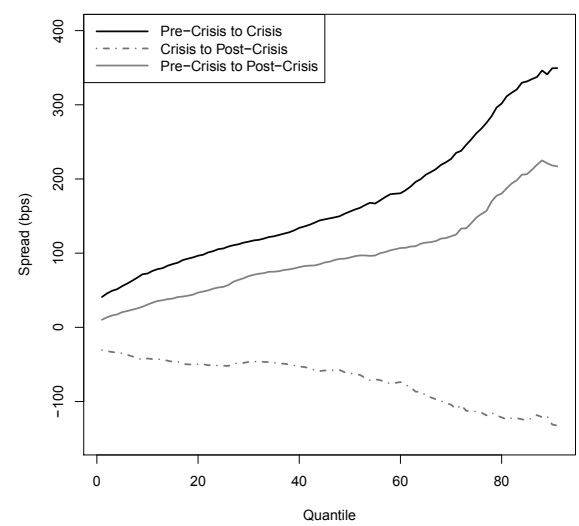

(b)

Fig. 5. Quantile Differences of Credit Spreads. The Figure shows the empirical quantile function (a) and observed differences (b) in credit spreads over the different periods at each quantile of the distribution.

For the decomposition from pre-crisis to crisis (Panel (a)), the results clearly show that most of the shift of the distribution of credit spreads can be attributed to changes in risk pricing but that there was also a sizable effect due to changes in the risk factors themselves. For the lowest deciles, changes in market factors account for an increase of $9 \mathrm{bps}$ out of a total change of $59 \mathrm{bps}$. This proportion increases to about half for the highest decile. Along the entire distribution, the effect due to changes in pricing is larger 
than the change due to changes in risk factors. The counterfactual results also show that the "kink" in the observed differences is caused by a relatively stronger effect of risk factors. The effects due to residuals are statistically insignificant and economically very small for the quantiles above the median. For the lower quantiles, the estimated effect due to changes in residuals is negative and statistically significant with an estimated effect of around 10 bps in absolute value.

Contrary to the first decomposition, we find that for the decomposition from crisis to post-crisis (Panel (b)) the effect of changes in risk factors is the effect causing the observed negative change and that the change due to changes in risk pricing is negligible. The effect of the changes by risk factors is negative and almost constant from the first decile to the median at -40 bps out of a total observed change of about -40 to $-60 \mathrm{bps}$. For the higher quantiles, the effect is much more pronounced and increases to -125 bps at the 9 th decile where the total observed effect is $-122 \mathrm{bps}$. The effect attributed to changes in risk pricing is comparatively small with an effect of $6 \mathrm{bps}$ at the first decile and $-15 \mathrm{bps}$ at the ninth decile and a linear decrease in between. The effects due to changes in risk pricing are all statistically insignificant. This shows that changes in market conditions have contributed to the decrease in corporate bond spreads as the effects of the crisis abated. The decrease in credit spreads after the crisis is almost completely due to changes in the risk factors. The risk premia after the crisis, however, have stayed at their elevated levels relative to the pre-crisis period. The fact that the effect due to changes in risk pricing is far smaller in this decomposition than in the first strongly suggests that investors have updated their beliefs about the riskiness of corporate bonds.

Finally, for the decomposition from pre-crisis to post-crisis (Panel (c)), we find that almost the entire increase in spreads is caused by changes in the pricing of corporate bonds. The observed change in spreads is an increase of $21 \mathrm{bps}$ at the first decile while they have increased by $89 \mathrm{bps}$ at the median and $213 \mathrm{bps}$ at the ninth decile. The increase caused by changes in risk pricing is estimated at 37, 85, and $190 \mathrm{bps}$, respectively. On the other hand, the effect caused by changes in risk factors themselves is estimated at $-3,7$, and 4 bps, respectively. The decomposition shows that changes in market factors is economically negligible and most of the change can be attributed to changes in pricing. Interpreting this in financial terms, these results imply that the change in credit spreads over the financial crisis is almost entirely caused by a reevaluation of the implications of a given level of a risk factor, i.e. increases in the pricing implications of a given risk factor. We interpret this as an increase in risk perception caused by the crisis. For the lower deciles, we again find a statistically significant negative effect.

Our results are consistent with learning models of asset pricing: once investors realize that a structural break has occurred they alter their risk pricing as they learn about the new parameters with adaptive learning rules. This learning introduces long-run risk resulting in permanent shifts after large shocks which makes investors more risk-averse resulting in higher prices of risk.

In each decomposition, we find that the effect of changes in residuals are either insignificant or economically very small. This indicates that the residuals in the quantile regressions are not systematically biased and that we have not omitted a relevant latent factor (Collin-Dufresne, Goldstein, and Martin, 2001) or use a misspecified model (Jaskowski, 2010). A systematic increase in residuals would indicate that changes in risk factors could have been caused by increases in the correlation of these factors. This does not seem to be the case as the residual effect in each decomposition is very small. In the decompositions from the pre-crisis period into the crisis and to the post-crisis period, we 


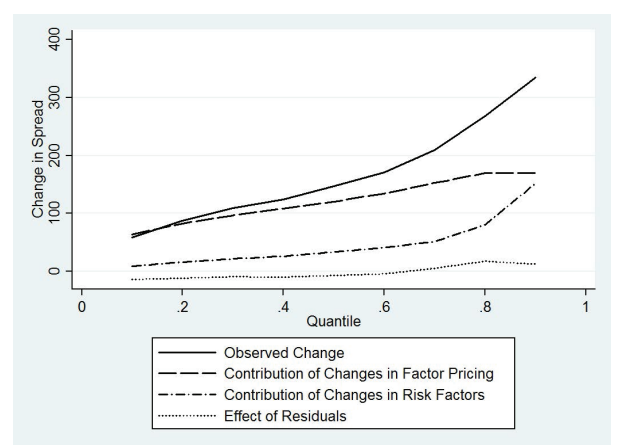

(a)

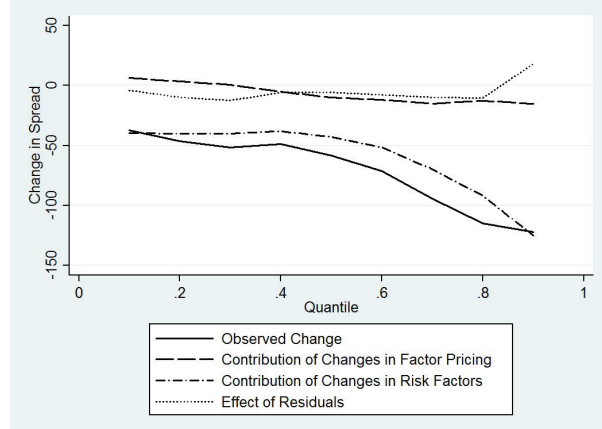

(b)

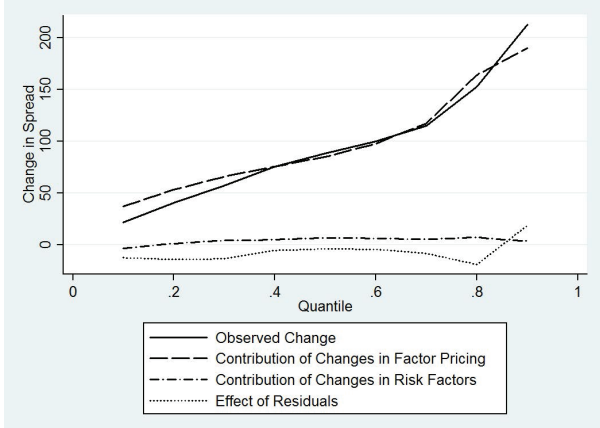

(c)

Fig. 6. Decomposition of Credit Spreads. The figure presents the results of the counterfactual decomposition in (8) for the three time steps from pre-crisis to crisis (Panel (a)), from crisis to post-crisis (Panel (b)), and from pre-crisis to post-crisis (Panel (c)). Results on the corresponding confidence bands and estimates can be found in Appendices $\mathrm{E}$ and $\mathrm{F}$, respectively.

find a economically meaningful negative residual effect. This could be the effect from a flight to quality during and after the crisis which would increase the prices of these bonds beyond what is implied by their riskiness leading to unexpectedly low yields and spreads.

\subsection{Effects of Different Risk Factors on Bond Spreads}

In the previous section, we used counterfactual decompositions to separate how much of the observed increase in credit spreads over recent years has been caused by changes in risk factors as observed in markets (i.e., the effect caused by covariates) and how much has been caused by changes in the pricing implication of a given level of a risk factor (i.e., the effect caused by coefficients). Motivated by the summary statistics in Table 2 we perform a sequential decomposition as described in Equation (9) to analyze the influence that various types of risk categories had on the effect caused by changes in all coefficients. In particular, we analyze the separate effects that changes in the pricing of default risk and liquidity risk 


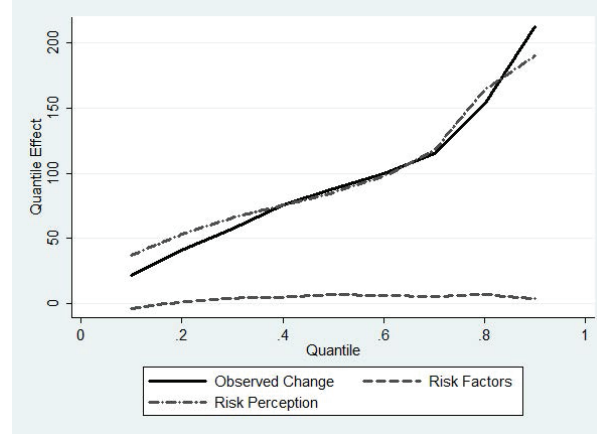

(a)

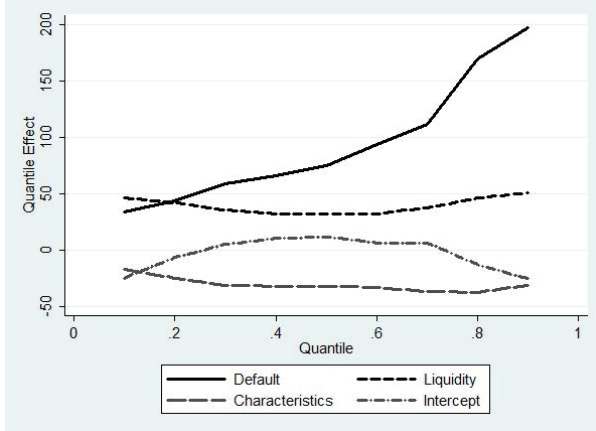

(b)

Fig. 7. Decomposition Results for Different Risk Factors (Pre-Crisis to Post-Crisis). The figure shows results from the counterfactual decomposition (Panel (a)) and the contribution of each risk factor to the change in risk perception (Panel (b)) between the pre- and post-crisis period.

have had on bond spreads. ${ }^{18}$ We emphasize that the interpretation of this effect does not depend on the risk factors remaining constant over time. On the contrary, the methodology explicitly accounts for changes in factors. Hence, the effect that we extract is the yield premium independent of the individual riskiness of a particular bond.

To save space we only report results for the decomposition from pre-crisis to postcrisis as this is the one that is central to our goal of determining the effect the crisis has had (results for the other two decompositions can be found in Appendix G). Table 5 reports results for the first and ninth quantile as well as the median change. The results for the three main effects is summarized in Figure 7. Panel (a) shows the total observed change in bond spreads (solid line) as well as the overall effects of the counterfactual decomposition (gray, dashed lines). The dashed line shows the effect attributable to observed movements in market factors while keeping the risk pricing at their initial levels, whereas the dasheddotted line shows the total effect that changes in risk perception has had. Panel (b) presents how changes in the perception of the various risk factors have affected bond spreads.

After accounting for the general shift in credit spreads by adjusting the intercept and dummies, we first adjust the impact of changes in the pricing of default risk. Figure $7(\mathrm{~b})$

18 This sequence of decomposition implicitly assumes that no interaction effects are present between the different components. In general, the cross-effects are included in the component that is added first. For instance, accounting first for default risk and then for liquidity risk implies that the effect that liquidity has on default risk is shown in the decomposition as part of the default effect. In unreported results, we have varied the sequence of the decompositions with qualitatively the same results. Hence, interaction effects seem to be only of second-order importance. This result contradicts the model by Chen, Cui, He, and Milbradt (2014), who find that additionally to "pure" default and liquidity risk the interaction terms "liquidity-driven-default" and "default-driven-liquidity" account for $25-40 \%$ of credit spread level. Note further that the choice of sequence of decompositions affects the decomposition results mainly in nonlinear models with interaction effects. We refrain from including interaction terms because the separation of covariates in main effects and interaction effects comes along with further assumptions. 
Table 5 Sequential Decomposition Results at Selected Quantiles

\begin{tabular}{|c|c|c|c|c|c|c|}
\hline & \multicolumn{2}{|c|}{ 10\% Quantile } & \multicolumn{2}{|c|}{ Median } & \multicolumn{2}{|c|}{ 90\% Quantile } \\
\hline & Estimate & $\begin{array}{l}\text { Std. } \\
\text { Error }\end{array}$ & Estimate & $\begin{array}{l}\text { Std. } \\
\text { Error }\end{array}$ & Estimate & $\begin{array}{r}\text { Std. } \\
\text { Error }\end{array}$ \\
\hline Observed Change & 21.81 & 2.02 & 88.55 & 3.30 & 212.70 & 11.43 \\
\hline Contr. by Risk Factors & -3.29 & 1.44 & 7.08 & 2.44 & 3.85 & 5.87 \\
\hline Contr. by Risk Pricing & 37.34 & 2.23 & 85.19 & 2.77 & 190.12 & 7.83 \\
\hline Intercept & -25.89 & 2.20 & 4.72 & 4.09 & 11.23 & 8.92 \\
\hline Default Coefficients & 33.72 & 1.29 & 74.80 & 1.65 & 196.98 & 8.05 \\
\hline Liquidity Coefficients & 45.87 & 3.19 & 31.45 & 2.46 & 50.64 & 10.17 \\
\hline Characteristics Coefficients & -17.22 & 1.14 & -32.29 & 1.09 & -31.61 & 5.78 \\
\hline Residuals & -12.23 & 1.62 & -3.72 & 1.67 & 18.74 & 6.27 \\
\hline
\end{tabular}

The table reports the results of the sequential decomposition described in (9), going from the pre-crisis to the post-crisis period, for the $10 \%, 50 \%$ and $90 \%$ quantile.

shows that relative to the pre-crisis period, the pricing implications of a given level of default risk have increased substantially. This does not directly imply that the contribution of credit risk (which would be risk factor multiplied by its coefficient) has increased. It does say, however, that a given ratio that we use to proxy for default risk carries a higher credit spread premium after the crisis than before. At the $10 \%$ quantile the increase due to the changes in default coefficients accounts for $34 \mathrm{bps}$ out of the total effect from changing risk pricing of $37 \mathrm{bps}$. At the median, the change due to default coefficient is $75 \mathrm{bps}$ out of $85 \mathrm{bps}$ and at the $90 \%$ quantile it is $197 \mathrm{bps}$ out of $190 \mathrm{bps}$. Hence, we find that the increase in the pricing of default risk is substantial in economic terms. We find that the pricing of liquidity risk has increased along all quantiles as well, but the increase is more uniform along the quantiles. At the $10 \%$ quantile, the increase due to changes in liquidity coefficients is 46 bps and thus much larger than the default coefficients effect. At the median, the effect is estimated at $31 \mathrm{bps}$ and at the $90 \%$ quantile it is 51 bps. These results indicate that liquidity effects are more pronounced in the investment grade segment. Institutional investors seem to be more concerned with illiquidity risk than before the financial crisis irrespective of actual levels of liquidity. The effects of the bond characteristics is negative along all quantiles with an estimated effect of -17 bps $(10 \%$ Quantile), -32 bps (Median), and -32 bps (90\% Quantile). This result implies that after controlling for default and liquidity risk, bonds with the same indenture data trade at higher prices (therefore lower yields and spreads) after the crisis than before. Note that if one were to add the bond characteristics to the liquidity variables, then the estimated liquidity effect would be much lower and only positive and economically meaningful for the highest quantiles (i.e., the investment grade segment).

One should note that the change due to the intercept and dummies is significant and economically quite large as shown in Table 5. A possible explanation for the size and direction of the effect is that it might capture changes in macroeconomic factors for which we cannot control in our cross-sectional estimation setting. The negative sign could be the result of the quantitative easing program of the Federal Reserve which may have lowered bond yields to levels lower than what one would expect given a company's risk factors. 
For the decomposition from the pre-crisis period to the crisis period, we find that pricing of default risk and liquidity increased substantially during the crisis. The effect of liquidity is largest (in absolute terms) for the lowest and highest quantiles. Hence, investment grade bonds were the bonds where changes in liquidity pricing had the greatest impact (in relative terms). Changes in default risk pricing increase along the quantiles. For the decomposition from the crisis to the post-crisis period, we find that the pricing of default risk remained approximately constant while liquidity pricing increased. These results suggest that adjustment in the pricing of default risk preceded the adjustments in the pricing of liquidity. This pattern is consistent with the model of He and Milbradt (2014) who model the interaction between default rates and second market liquidity on the bond market. This feedback loop causes illiquidity concerns to rise after an increase in default rates. Our results suggest that bond market investors reacted to this by demanding higher compensation for liquidity risk after default rates increased during the crisis.

Our results suggest that investors attribute more importance to default and liquidity risk after the crisis. For investment grade bonds the effect due to liquidity is larger than that for default risk. For quantiles higher than the $20 \%$ quantile, increases in spreads due to credit risk outweight the liquidity effect. Moreover, we find that the increase in credit spreads due to liquidity is roughly uniform across the distribution of bonds with an increase of about 30 - 50 bps. In contrast to that, changes in the pricing of default are much more pronounced in the high-yield segment.

\subsection{Robustness Checks}

To validate our main results, we carry out a series of robustness checks. To conserve space, all estimation results for the robustness tests are reported in the Appendix. First, we estimate year-on-year decompositions for the years in each period to confirm that the pricing relationships do not change fundamentally on a yearly basis. Second, we confirm that the results are not driven by quantile jumps by estimating the decompositions using OLS regression at the mean and reestimating the decompositions using the constant subsample of bonds for which an observation in each year is available. Third, we condense the default and liquidity factors using (robust) principle components analysis (PCA) and repeat the counterfactual experiments. Finally, we confirm that the results are not dependent on the annual data frequency and the specific dates chosen for the crisis.

For the year-on-year decompositions in each period we find that the pricing relationships do not change fundamentally on a yearly basis. The results confirm that from 2005 to 2006 (Table H.1)and 2006 to 2007 (Table H.2) the components of bond spreads have remained very similar and we find no statistically significant effect for any quantile. Similar results were obtained for 2010 to 2011 (Table H.4). This indicates that in these periods risk perception and risk factors have remained at similar levels within these periods. For the crisis period, we find an effect due to both risk factors and risk pricing. Hence, the crisis period is much less homogeneous than the period before or after. Given the magnitude of the economic shock, this result was expected.

The results for the decompositions based on OLS regression are reported in Tables I.1,I.2, and I.3 in Appendix I. The results based on OLS regression are similar qualitatively to the results based on quantile regression. However, the estimated effects are generally larger in magnitude. In particular, the contribution by residuals is much larger. This indicates that quantile regression is more appropriate for the linear model specified 
in (10) and that for the OLS regression the errors are correlated with the covariates. The results for the decompositions based on the subsample of bonds for which observations are available in each year is reported in Tables K.1, K.2, and K.3 in Appendix K. We find that the results are very similar to the results using the complete sample. We also repeat the sequential decomposition for each test and found that these results are also very similar to the original results. In particular, we find the same effects for the bond characteristics. This confirms that the change in pricing of these is not due to a change in the composition of the sample. A possible explanation for the finding is that the preferences of bond investors may have changed over the crisis. Age, maturity, and coupon are all related to the duration of a bond. Given that the term structure of interest rates has changed substantially over the time frame considered, the changes in the pricing of bond characteristics could be due to investment and hedging needs. An alternative interpretation would be that the bond characteristics are all related to the liquidity of a bond. This interpretation would decrease the liquidity effects found substantially. We conclude from these results that quantile jumps, i.e. bonds moving within the distribution of credit spreads, are not affecting the results.

The regression model (10) contains a large number of covariates. Although the regression results in Section 5.1 show that each variable has explanatory power the amount of variables may confound the interpretation of results. Hence, we apply PCA to the default and liquidity variables separately and extract a single measure of default and liquidity risk as the first principle component each. As the variables are not close to normally distributed we use robust PCA. The results, reported in Appendix J confirms the initial results that changes in risk pricing caused the increase of credit spreads after the crisis relative to pre-crisis levels. Compared to the full specification, the effect caused by changes in risk factors is smaller while the residual effect is larger. This is to be expected as the principle components have less variation and therefore can account for less of the cross-sectional variation. The sequential decomposition using the PCA factors yields the same conclusions as the complete decomposition.

In order to avoid any arbitrary definition of the crisis period, we test the sensitivity of our main findings to the choice of different dates. Because we only use one date (July $1^{\text {st }}$ ) of information per year, our data covers only limited information in the time dimension. For example, July 1, 2008 was almost three months before Lehmans bankruptcy and July 1, 2009, was almost nine months after this significant event. We therefore repeat the analysis using quarterly data. However, this approach comes along with a drawback: Because not all firms disclose their balance sheet figures quarterly, the quarterly sample will be biased towards larger firms. When we utilize quarterly data, our results (reported in Tables L.1, L.2, and L.3 in Appendix L) remain qualitatively and quantitatively very similar. Overall, the observed changes with quarterly data are larger. Again, most of the change from the pre-crisis to the post-crisis period is attributed to changes in risk pricing. In contrast to the yearly data, changes in market risk factors contribute to a decrease in credit spreads for the higher quantiles. This is due to the fact that there is more time variation in the quarterly data. Using quarterly data allows us to further test whether our conclusions are robust to defining different time periods for the crisis. Therefore, we estimate the decompositions using quarterly data with the various beginning and end dates for the crisis. As start date, we use any of the four quarters in 2007 and as end date, we use any 
of the four quarters in 2009. This results in 16 different time periods for the crisis. We find that our main results of the decompositions are not materially altered. ${ }^{19}$

\section{Conclusion}

This paper investigates empirically whether lasting shifts in risk perception are responsible for the sustained increase in corporate bond spreads from 2005 to 2011 . We use a methodology novel to the empirical finance literature which allows us to explicitly account for changes in market risk factors and separating out the effect that the pricing of these factors has. This gives us an estimate of what spreads would have been if risk perception had not changed. The remaining difference, then, can be interpreted as an estimate of the effect that changes in the pricing structure have had on the levels of bond spreads. Using this decomposition, we find that most of the increase in bond spreads are due to changes in risk perception, and thus, due to changes in the pricing of risk. While the movement of risk factors has increased spreads as the financial crisis unfolded, these effects are reversed as the crisis abated. However, bond spreads have not returned to their pre-crisis levels. This indicates that the financial crisis has caused enduring shifts in risk attitudes, and thus, changed the pricing of risk. We therefore provide an important contribution by adding another mosaic to solve the credit spread puzzle.

We use known risk factors to decompose credit spreads into its priced risk components. Thereby, we differentiate between factors that are related to the specific bond, to its liquidity, and its default risk. By estimating regressions at different quantiles of the distribution of credit spreads we therefore obtain more direct estimates of how risk factors simultaneously contribute to the level of credit spreads. Our results show that these factors can account for much of the cross-sectional variation in credit spreads and confirm several results in the literature. We find a very pronounced effect of illiquidity on credit spreads. The quantile curves for the risk factors clearly demonstrate large quantile effects. The results indicate that standard mean regressions may misrepresent the risk premia of bonds because of the non-linear relationship we find.

By using these risk factors, our identification strategy provides explicit estimates of how changes in these factors have influenced credit spreads and how much of the changes in credit spreads before and after the recent financial crisis are due to changes in the pricing of these risk factors. The results show that most of the increase in credit spreads over the financial crisis is due to a spike in risk perception. Relative to pre-crisis levels, credit spreads have increased between 22 (first decile) and 213 bps (last decile) with an increase of $89 \mathrm{bps}$ at the median of the distribution. Changes in actual risk factors have contributed to a decrease of spreads by 3 bps at the first decile and an increase of approximately 2 to 7 bps at any other decile. The remainder of the total increase in spreads is then due to changes in risk perceptions. This shows that markets have significantly revalued what a given risk factor should carry as a premium in the corporate bond market. The sequential decomposition highlights the fact that during the crisis default premia have spiked which have not returned afterwards. Liquidity premia have increased both during and after the crisis almost uniformly for all bonds.

A possible explanation for this finding is provided by considering ambiguity averse investors. The financial crisis has increased the perception of model risk which has caused

$\overline{19}$ Results are available from the authors upon request. 
institutional investors to demand higher risk premia for a given level of risk as they now assign a higher probability to low utility states (Boyarchenko, 2012). In a similar way as Malmendier and Nagel (2011) and Cohn, Engelmann, Fehr, and Maréchal (2014), who demonstrate how previous experiences of risky asset returns significantly affect the willingness to take financial risk, we show that institutional investors change their risk perception due to a recent crisis event, and thus, price risk factors differently. Given this broad empirical evidence, standard economic models have to allow not only for statedependent risk factors but also for changing risk preferences. More precisely, in a further step a structural model is needed that can incorporate the salient features of bond spreads described in this paper. A possible direction would be to adapt the time-varying fear model of Drechsler (2013) to the bond market or to extend the structural credit risk model of Chen, Cui, He, and Milbradt (2014) by allowing risk preferences and the pricing of risk to alter. We leave this for future research.

In addition, our results provide an explanation for the structure in the residuals found by Collin-Dufresne, Goldstein, and Martin (2001). Their study looks at the determinants of changes in credit spreads using time-series regressions on each bond. They found that most of the variation in the residuals could be explained by the first principal component. From this, they concluded that bond and equity markets are segmented and that an underlying bond factor had been omitted. A number of follow-up studies have provided alternative interpretations of this result. Our study suggests that this latent factor is due to changes in risk perception over time. In a time-series regression, the estimated coefficient for each risk factor is constant. Hence, if these coefficients are in fact time-varying across the bond market, artificial cross-correlation is created in the residuals.

An interesting further question would be to examine whether and how results differ among sub-samples. For instance, one could examine if the classification into junk and investment grade bond by itself carries a risk premium above and beyond ratings and default related risk proxies. In a similar vein, Friewald, Jankowitsch, and Subrahmanyam (2012) separate bond trades into retail and institutional trades and examine whether illiquidity has different effects depending on trade size. In our research setup, this would entail comparing the changes in risk perception of institutional and retail investors. Finally, a future study might quantify the persistence of such discovered changes in risk aversion.

\section{References}

Acharya, V., and Lars Pedersen, 2005, Asset pricing with liquidity risk, Journal of Financial Economics 77, 375-410.

Alary, David, Christian Gollier, and Nicolas Treich, 2010, The effect of ambiguity aversion on risk reduction and insurance demand, Working Paper.

Allen, Franklin, and Elena Carletti, 2008, The role of liquidity in financial crises, Working Paper.

Amihud, Yakov, 2002, Illiquidity and stock returns: Cross-section and time-series effects, Journal of Financial Economics 5, 31-56.

, and Haim Mendelson, 1986, Asset pricing and the bid-ask spread, Journal of Financial Economics 2, 223-249.

Antonczyk, Dirk, Bernd Fitzenberger, and Katrin Sommerfeld, 2010, Rising wage inequality, the decline of collective bargaining, and the gender wage gap, Labour Economics 17, 835-847. 
Bacchetta, Philippe, Cédric Tille, and Eric van Wincoop, 2012, Self-fulfilling risk panics, American Economic Review 102, 3674-3700.

Bansal, Ravi, and Ivan Shaliastovich, 2011, Learning and asset-price jumps, Review of Financial Studies 24, 2738-2780.

Bao, Jack, Jun Pan, and Jiang Wang, 2011, The illiquidity of corporate bonds, Journal of Finance 66, 911-946.

Barone-Adesi, Giovanni, Loriano Mancini, and Hersh Shefrin, 2014, Sentiment, risk aversion and time preferences, Swiss Finance Institute Research Paper No. 12-21.

Basak, Suleyman, 2000, Model of dynamic equilibrium asset pricing with heterogenous beliefs and extraneous risk, Journal of Economic Dynamics and Control 24, 63-95.

— , and Domenico Cuoco, 1998, An equilibrium model with restricted stock market participation, Review of Financial Studies 11, 309-341.

Bassett, G., and R. Koenker, 1982, Tests of linear hypotheses and L1 estimation, Econometrica 50, 1577-1583.

Berger, Allen N., and Christa H.S. Bouwman, 2009, Bank liquidity creation, Review of Financial Studies 22, 3779-3837.

Bhamra, Harjoat, Lars-Alexander Kuehn, and Ilya Strebulaev, 2010, The aggregate dynamics of capital structure and macroeconomic risk, Review of Financial Studies 23, 41874241 .

Bhamra, Harjoat, and Raman Uppal, 2009, The effect of introducing a non-redundant derivative on the volatility of stock-market returns when agents differ in risk aversion, Review of Financial Studies 22, 2303-2330.

, 2014, Asset prices with heterogeneity in preferences and beliefs, Review of Financial Studies 27, 519-580.

Bharath, Sreedhar T., and Tyler Shumway, 2008, Forecasting default with the Merton distance to default model, Review of Financial Studies 21, 1339-1369.

Black, Fisher, and John Cox, 1976, Valuing corporate securities: Some effects of bond indenture provisions, Journal of Finance 30, 351-367.

Blinder, Alan S., 1973, Wage discrimination: Reduced form and structural estimates, Journal of Human Resources 8, 436-455.

Blume, Marshall E., Donald B. Keim, and Sandeep A. Patel, 1991, Returns and volatility of low-grade bonds: 1977-1989, Journal of Finance 46, 49-74.

Bongaerts, Dion, Frank De Jong, and Joost Driessen, 2011, Derivative pricing with liquidity risk: Theory and evidence from the credit default swap market, Journal of Finance 66, 203-240.

Borovicka, Jaroslav, 2015, Survival and long-run dynamics with heterogeneous beliefs under recursive preferences, New York University.

Boyarchenko, Nina, 2012, Ambiguity shifts and the 2007-2008 financial crisis, Journal of Monetary Economics 59, 493-507.

Brunnermeier, Markus, 2009, Deciphering the liquidity and credit crunch 2007-2008, Journal of Economic Perspectives 23, 77-100.

Campbell, John Y., and Glen B. Taksler, 2003, Equity volatility and corporate bond yields, Journal of Finance 63, 2321-2349.

Chen, Hui, 2010, Macroeconomic conditions and the puzzle of credit spreads and capital structures, Journal of Finance 65, 2171-2212.

- Rui Cui, Zhiguo He, and Konstantin Milbradt, 2014, Quantifying liquidity and default risks of corporate bonds over the business cycle, NBER Working Paper No. 20638. 
Chen, Long, Pierre Collin-Dufesne, and Robert S. Goldstein, 2009, On the relation between the credit spread puzzle and the equity premium puzzle, Review of Financial Studies 22, $3367-3409$

Chen, Long, David A. Lesmond, and Jason Wei, 2007, Corporate yield spreads and bond liquidity, Journal of Finance 62, 119-149.

Chernozhukov, Victor, Iván Fernández-Val, and Blaise Melly, 2013, Inference on counterfactual distributions, Econometrica 81, 2205-2268.

Cohn, Alain, Jan Engelmann, Ernst Fehr, and Michel André Maréchal, 2014, Evidence for countercyclical risk aversion: An experiment with financial professionals, American Economic Review 105, 860-885.

Collin-Dufesne, Pierre, Michael Johannes, and Lars Lochstaer, 2013, Parameter learning in general equilibrium: The asset pricing implications, NBER Working Paper 19705.

Collin-Dufresne, Pierre, Robert S. Goldstein, and J. Spencer Martin, 2001, The determinants of credit spread changes, Journal of Finance 56, 2177-2207.

Dick-Nielsen, Jens, Peter Feldhütter, and David Lando, 2012, Corporate bond liquidity before and after the onset of the subprime crisis, Journal of Financial Economics 103, 471-492.

Drechsler, Itamar, 2013, Uncertainty, time-varying fear, and asset prices, Journal of Finance $68,1843-1889$.

Duffie, Darrell, and David Lando, 2001, Term structure of credit spreads with incomplete accounting information, Econometrica 69, 633-664.

Duffie, Darrell, and Kenneth Singleton, 1999, Modelling term structures of defaultable bonds, Review of Financial Studies 12, 687-720.

Dumas, Bernard, 1989, Two-person dynamic equilibrium in the capital market, Review of Financial Studies 2, 157-188.

, Alexander Kurshev, and Raman Uppal, 2009, Equilibrium strategies in the presence of sentiment risk and excess volatility, Journal of Finance 64, 579-629.

Edwards, Amy K., Lawrence E. Harris, and Michael S. Piwowar, 2007, Corporate bond market transaction costs and transparency, Journal of Finance 56, 1421-1451.

Elton, Edwin J., Martin J. Gruber, Deepak Agrawal, and Christopher Mann, 2001, Explaining the rate spread on corporate bonds, Journal of Finance 56, 247-277.

Fecht, Falko, Roland Füss, and Philipp Rindler, 2014, Corporate transparency and bond liquidity, School of Finance Working Paper No. 2014/4.

Feldhütter, Peter, 2012, The same bond at different prices: Identifying search frictions and selling pressures, Review of Financial Studies 25, 1155-1206.

Fortin, Nicole, Thomas Lemieux, and Sergio Firpo, 2011, Decomposition methods in economics, in Orley Ashenfelter, and David Card, ed.: Handbook of Labor Economics, Vol. 4, Part A . pp. 1-102 (Elsevier).

Friewald, Nils, Rainer Jankowitsch, and Marti G. Subrahmanyam, 2012, Illiquidity or credit deterioration: A study in the US corporate bond market during financial crises, Journal of Financial Economics 105, 18-36.

Gagliardini, Patrick, Paolo Porchia, and Fabio Trojani, 2009, Ambiguity aversion and the term structure of interest rates, Review of Financial Studies 22, 4157-4188.

Ghirardato, Paul, and Massimo Marinacci, 2001, Risk, ambiguity, and the separation of utility and beliefs, Mathematics of Operations Research 26, 864-890.

Giesecke, Kay, Francis A. Longstaff, Stephen Schaefer, and Ilya Strebulaev, 2011, Corporate bond default risk: A 150-year perspective, Journal of Financial Economics 102, $233-250$. 
Goldstein, M., E. Hotchkiss, and E. Sirri, 2007, Transparency and liquidity: A controlled experiment on corporate bonds, Review of Financial Studies 20, 235-273.

Gosling, Amanda, Stephen Machin, and Costas Meghir, 2000, The changing distribution of male wages in the UK, Review of Economic Studies 22, 689-722.

Green, Richard C., Burton Hollifield, and Norman Schürhoff, 2007, Financial intermediation and the costs of trading in an opaque market, Review of Financial Studies 20, $275-314$

Guerreri, Federico L., Gregory R. Stone, and James A. Sundali, 2012, Fear in asset allocation during and after stock market crashes: An experiment in behavioral finance, The Journal of Behavioral Finance and Economics 2, 50-81.

Guiso, Luigi, Paola Sapienza, and Luigi Zingales, 2013, Time varying risk aversion, EIEF Working Paper 22/13.

Hansen, Lars, 2007, Beliefs, doubts, and learning: Valuing macroeconomic risk, American Economic Review 97, 1-30.

He, Zhiguo, and Konstantin Milbradt, 2014, Endogenous liquidity and defaultable bonds, Econometrica 82, 1443-1508.

Hens, T., and C. Reichlin, 2013, Three solutions to the pricing kernel puzzle, Review of Finance 17, 1065-1098.

Hilscher, Jens, and Mungo Wilson, 2013, Credit ratings and credit risk: Is one measure enough?, Working Paper, Oxford University and Brandeis University.

Huang, Jing-Zhi Jay, and Ming Huang, 2012, How much of corporate-treasury yield spread is due to credit risk?, Review of Asset Pricing Studies 2, 153-202.

Jaskowski, Marcin Y., 2010, Credit spreads, factors, and noise, Unpublished Working Paper.

Kim, Young Se, 2006, Learning, structural breaks, and asset-return dynamics, Mimeograph, Federal Reserve St. Louis.

Lettau, Martin, and Sydney C. Ludvigson, 2001, Resurrecting the (C)CAPM: A crosssectional test when risk premia are time-varying, Journal of Political Economy 109, 12381286.

Lin, Hai, Junbo Wang, and Chunchi Wu, 2011, Liquidity risk and expected corporate bond returns, Journal of Financial Economics 99, 628-650.

Longstaff, Francis, Sanjay Mithal, and Eric Neis, 2005, Corporate yield spreads: Default risk or liquidity? New evidence from the credit default swap market, Journal of Finance 60, 2213-2253.

Longstaff, Francis, Jun Pan, Lasse Pedersen, and Kenneth Singleton, 2011, How sovereign is sovereign credit risk, American Economic Review: Macroeconomics 3, 75-103.

Machado, José, and José Mata, 2005, Counterfactual decomposition of changes in wage distributions using quantile regression, Journal of Applied Econometrics 20, 445-465.

Malmendier, Ulrike, and Stefan Nagel, 2011, Depression babies: Do macroeconomic experiences affect risk taking?, Quarterly Journal of Economics 126, 373-416.

Melly, Blaise, 2005, Decomposition of differences in distribution using quantile regression, Labour Economics 12, 577-590.

, 2006, Estimation of counterfactual distributions using quantile regression, Unpublished Manuscript, University of St. Gallen.

Oaxaca, Ronald, 1973, Male-femal wage differentials in urban labor markets, International Economic Review 14, 693-709.

Pan, Jun, and Kenneth Singleton, 2008, Default and recovery implicit in the term structure of sovereign CDS spreads, Journal of Finance 63, 2345-2384. 
Parzen, M., L. Wei, and Z. Ying, 1994, A resampling method based on pivotal estimating functions, Biometrika 81, 341-350.

Prieto, Rodolfo, 2013, Dynamic equilibrium with heterogeneous agents and risk constraints, Working Paper, Boston University.

Roll, Richard, 1984, A simple implicit measure of the effective bid-ask spread in an efficient market, Journal of Finance 39, 1127-1139.

Shefrin, Hersh, 2001, On kernels and sentiment, mimeo.

, 2009, How psychological pitfalls generated the global financial crisis, in L. Siegel, ed.: Voices of Wisdom: Understanding the Global Financial Crisis (CFA Institute: Charlottesville, VA).

Timmermann, Allen, 2001, Structural breaks, incomplete information, and stock prices, Journal of Business and Economic Statistics 19, 299-314.

Warga, Arthur D., 2004, An overview of the regulation of the bond markets, Report to the US Senate Banking Committee.

White, Halbert, 1980, A heteroskedasticity-consistent covariance matrix and a direct test for heteroskedasticity, Econometrica 48, 817-838. 